
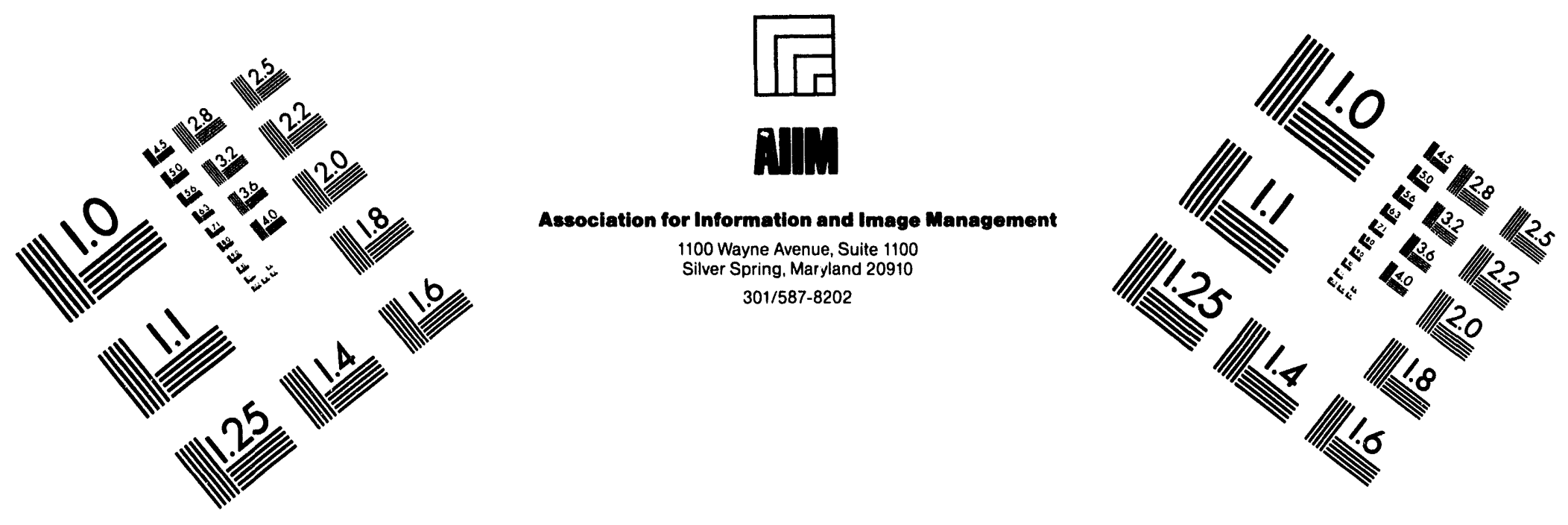

\title{
Centimeter
}

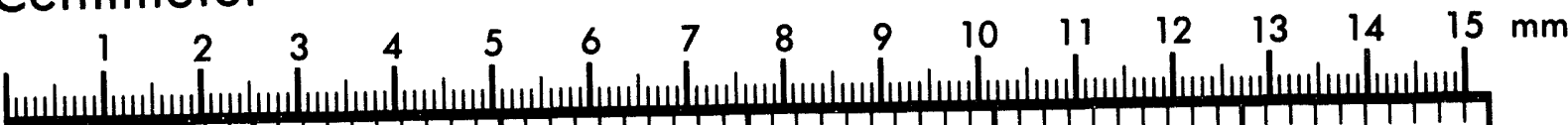

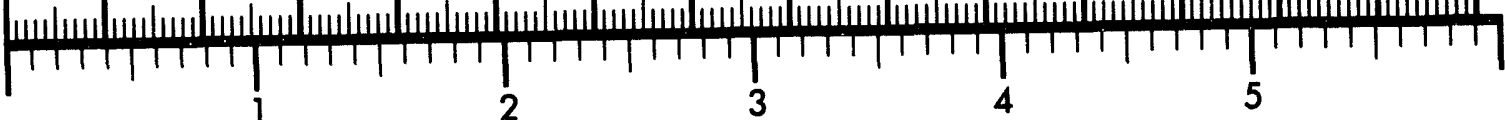
Inches

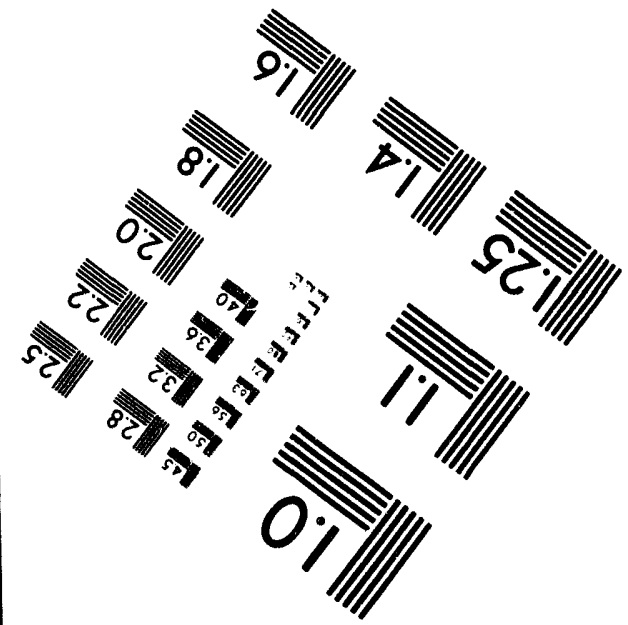

MANUFACTURED TO AIIM STANDARDS BY APPLIED IMAGE, INC.

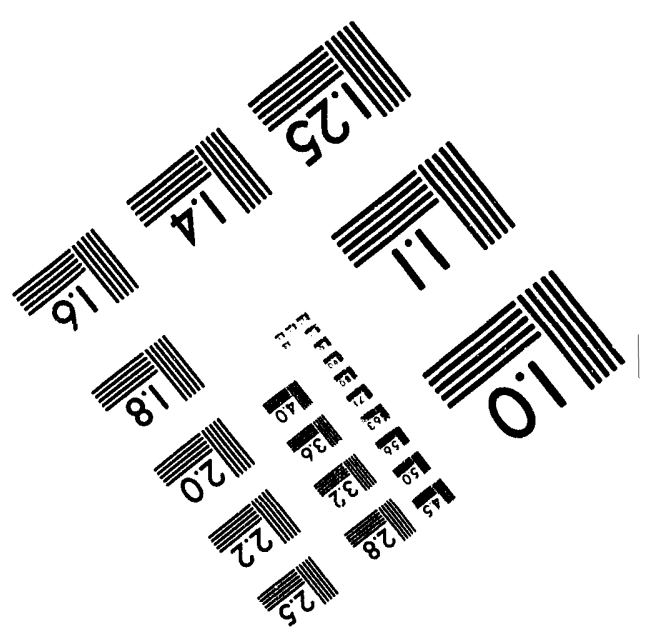



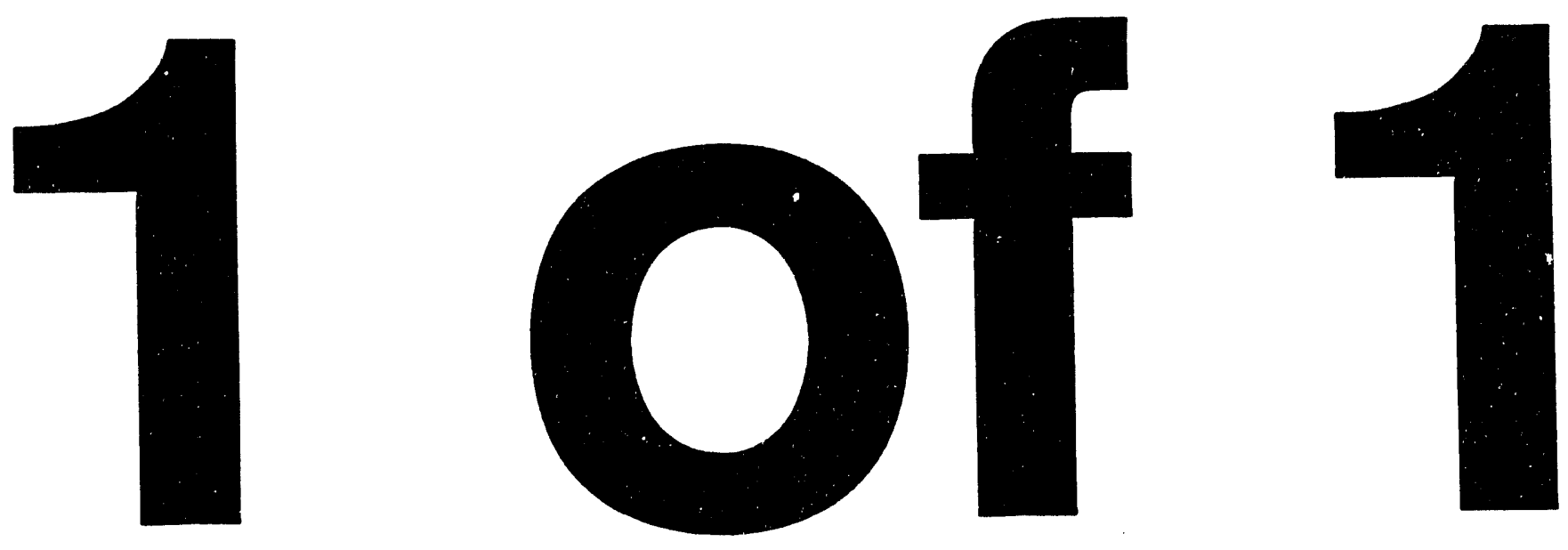
KCP-613-5431

Distribution Category UC-706

Approved for public release; distribution is unlimited.

\section{ELECTRON BEAM WELD DEVELOPMENT ON A FILTER PACK ASSEMBLY.}

J. P. Dereskiewicz

Published June 1994

Final Report

J. P. Dereskiewicz, Project Leader 


\section{Contents}

$\begin{array}{ll}\text { Section } & \text { Page }\end{array}$

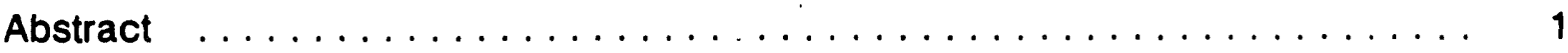

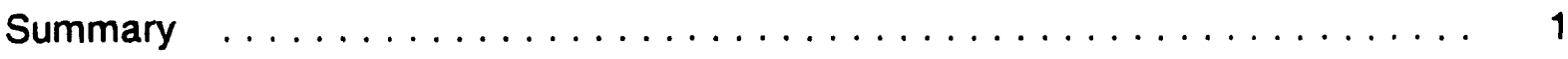

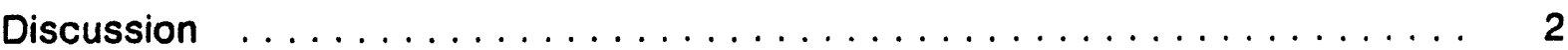

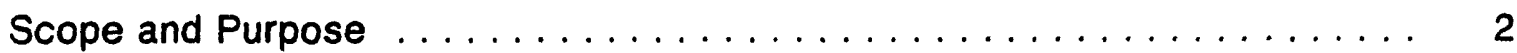

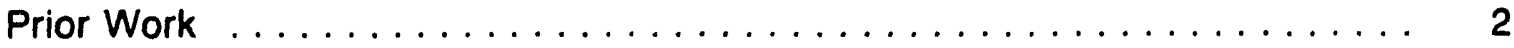

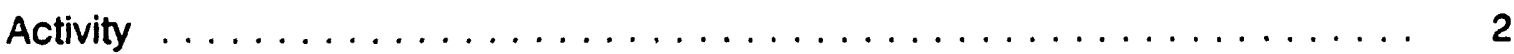

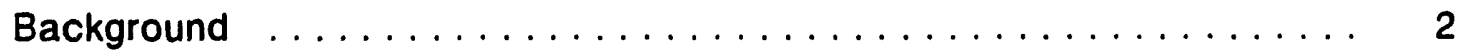

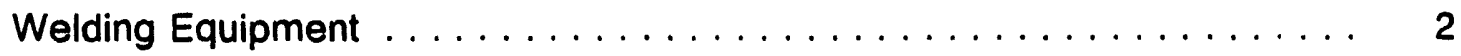

Penetration Study $\ldots \ldots \ldots \ldots \ldots \ldots \ldots \ldots \ldots \ldots \ldots \ldots \ldots \ldots$

Joint Tolerance Study $\ldots \ldots \ldots \ldots \ldots \ldots \ldots \ldots \ldots \ldots$

Weldment Cleaning Study $\ldots \ldots \ldots \ldots \ldots \ldots \ldots$

Temperature Study $\ldots \ldots \ldots \ldots \ldots \ldots \ldots \ldots \ldots$. . . . . . . . . . . . . .

Optical Viewing System Upgrade $\ldots \ldots \ldots \ldots \ldots \ldots \ldots \ldots \ldots$

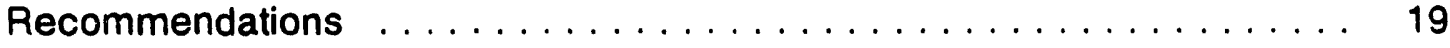

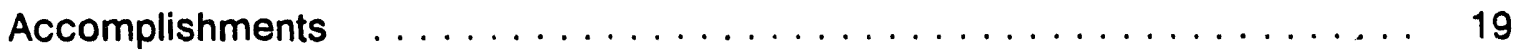

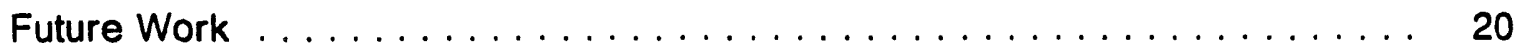

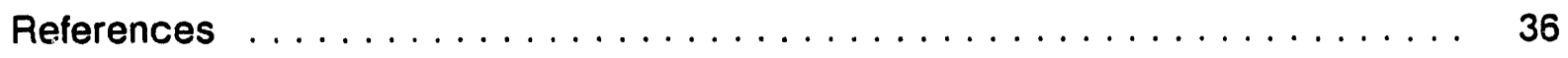

Appendix. Initial WPS Qualification Micrographs $\ldots \ldots \ldots \ldots \ldots$ 


\section{Illustrations}

Figure

Page

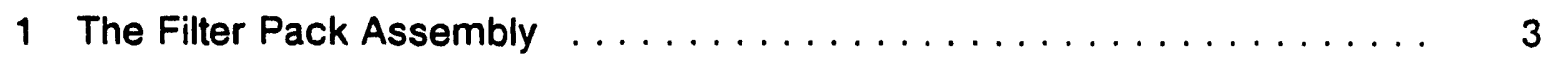

$260 \mathrm{kV}$ High Voltage Electron Beam Welding System . . . . . . . . . . 4

3 Closed Square Butt Joint on the Input Cover $\ldots \ldots \ldots \ldots \ldots$

4 Closed Lapped Corner Joint on the Output Cover . . . . . . . . . . . 5

5 Sectioning Locations on Test Weldment Cover Patterns $\ldots \ldots \ldots \ldots$

6 Bead on Test Weldment for Input Cover Pattern $\ldots \ldots \ldots \ldots \ldots \ldots$

7 Bead on Test Weldment for Large Cover Pattern $\ldots \ldots \ldots \ldots \ldots \ldots$

8 Bead on Test Weldment for Small Cover Pattern . . . . . . . . . . . 9

9 Bead on Test Weldment for Output Cover Pattern $\ldots \ldots \ldots \ldots$

10 Input, Large and Small Covers Welded to a Cast Weldment . . . . . . . 11

11 Weld Penetration Values at Various Locations on the Cast Weldment . . . 12

12 Weld Penetration Values at Various Locations on the Cast Weldment . . . 13

13 Output Cover Welded to a Cast Weldment $\ldots \ldots \ldots \ldots \ldots \ldots$

14 Weld Penetration Values at Various Locations on the Cast Weldment . . . 15

15 Weld Penetration Values at Various Locations on the Cast Weldment . . . 16

16 Test Weldment Used in the Joint Tolerance Study . . . . . . . . . . 18

17 Surface Response Curve Plotting Joint Gap Versus Beam Alignment . . . 21

18 Surface Response Curve Plotting Step Versus Beam Alignment . . . . . . 22

19 Surface Response Curve Plotting Joint Gap Versus Step . . . . . . . . . 23

20 Joint Tolerances Machined Into Cast Weldment for the Input Cover Weld ................................. 24 
21 Joint Tolerances Machined Into Cast Weldment for the Large Cover Weld

22 Joint Tolerances Machined Into Cast Weldment for the Small Cover

23 Joint Tolerances Machined Into Cast Weldment for the Output Cover

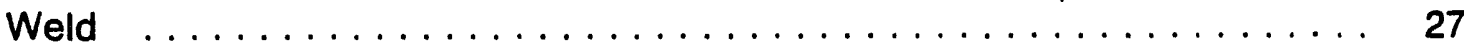

24 Elemental Analysis of Polyester Fiber Cleaning Material . . . . . . . . . 28

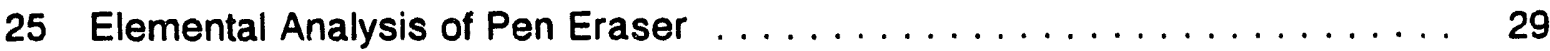

26 Elemental Analysis of Pencil Eraser $\ldots \ldots \ldots \ldots \ldots \ldots \ldots \ldots \ldots \ldots \ldots$

27 Thermocouple Locations on Cast Weldment $\ldots \ldots \ldots \ldots \ldots \ldots \ldots \ldots$

$2860 \mathrm{kV}$ High-Voltage Electron Beam Viewing System $\ldots \ldots \ldots \ldots \ldots$

29 Improved Viewing System on $60 \mathrm{kV}$ Electron Beam Welding System . . . . 34

30 Modified Electron Beam Control Cabinet $\ldots \ldots \ldots \ldots \ldots \ldots \ldots$

A-1 Qualification Test Weldment Showing Cross-Sectional Locations on the Input Large and Small Covers $\ldots \ldots \ldots \ldots \ldots \ldots \ldots \ldots$

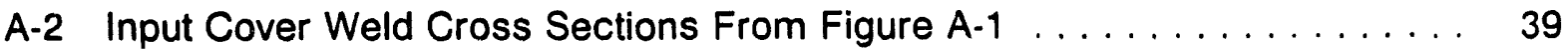

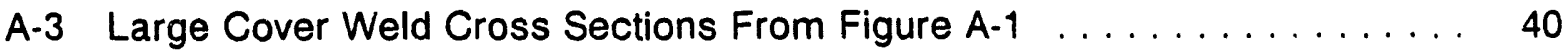

A-4 Small Cover Weld Cross Sections From Figure A-1 $\ldots \ldots \ldots \ldots \ldots \ldots$

A-5. Qualification Test Weldment Showing Cross-Sectional Locations on the

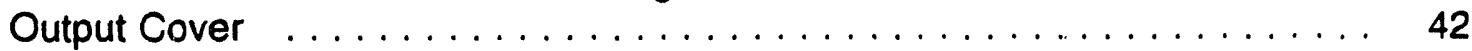

A-6 Output Cover Weld Cross Sections From Figure A-5 $\ldots \ldots \ldots \ldots \ldots \ldots$ 


\section{Tables}

Number $\quad$ Page

1 Beam Current Variance on Cast Weldment $\ldots \ldots \ldots \ldots \ldots \ldots \ldots$

2 Three-Variable Three-Level Box-Behnken Statistical Matrix Used to

3 Level Definitions for the Three-Variable Statistical Study on Joint

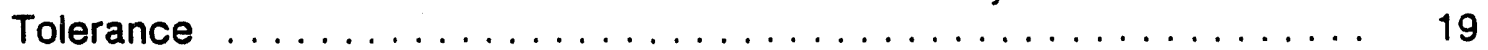

4 Electron Beam Weld Variable Identification . . . . . . . . . . . . . . . . 20

5 Maximum Recommended Peak Temperature Exposure $\ldots \ldots \ldots \ldots \ldots$

6 Peak Temperature Values on Input Cover Welds $\ldots \ldots \ldots \ldots \ldots$

7 Peak Temperature Values on Input Cover GTA Repair . . . . . . . . . . . 32 


\section{Abstract}

A continuous electron beam welding procedure was developed to replace the manual gas tungsten arc welding procedure on the Filter Pack Assembly. A statistical study was used to evaluate the feasibility of electron beam welding 6061-T6 aluminum covers to A356 cast weldments throughout the joint tolerance range specified on product drawings. Peak temperature exposures were not high enough to degrade the heat sensitive electrical components inside the cast weldment. Actual weldments with alodine coating on the weld joint area were successfully cleaned using a nonmetallic fiberglass brush cleaning method.

\section{Summary}

The objectives of this development project were to (1) establish weld parameters that would satisfy weld design specifications,

(2) evaluate this preliminary weld procedure against variation in joint tolerances, (3) establish a nonmetallic cleaning method to thoroughly remove alodine coating from the weld joint area, (4) evaluate weldment peak temperature exposures from electron beam welding and gas tungsten arc welding repair, and (5) evaluate the feasibility of improving the viewing optics on the welding system.

It was determined that the electron beam welding process can successfully weld the four aluminum covers to the A356 cast housing and meet design specifications throughout the joint tolerance range $A$ continuous electron beam weld using a qualified welding procedure specification did not significantly increase peak temperatures on weldments relative to manual gas tungsten arc welding. Actual weldments with alodine coating on the weld joint area were successfully cleaned using a nonmetallic fiberglass brush cleaning method. Finally, the viewing optics on the welding system were significantly improved using a miniaturized camera and remote iris, focus, and cross-hair adjustment capabilities. 


\section{Discussion}

\section{Scope and Purpose}

This development activity was initiated to evaluate the electron beam welding process used on four 6061-T6 aluminum covers: input cover, large cover, output cover, and small cover, P/N 389758. These four covers would be welded to an A356 aluminum cast machined housing for the Filter Pack Assembly used on a weapon retrofit program.

The following were specific objectives of this project:

- Establish weld parameters to meet design specifications,

- Evaluate selected weld parameters against joint tolerance variations,

- Establish a nonmetallic cleaning method to thoroughly remove alodine coating from the weld joint area,

- Evaluate weldment peak temperature exposures from electron beam welding and gas tungsten arc weld repair, and

- Evaluate the feasibility of improving the viewing optics on a welding system.

\section{Prior Work}

Previous electron beam welding experience has been gained from development on an earlier Filter Pack Assembly. 1 That experience was used as the building blocks in fulfilling the objectives of this activity.

\section{Activity}

\section{Background}

The Filter Pack assembly (Figure 1) is used to condition signals between a preflight controller and the center case section components of the weapon. This assembly consists of an A356-T6 aluminum investment casting housing with various filters and electrical components housed in four different cavities. Each of these four cavities has welded aluminum covers that provide environmental and electromagnetic radiation protection. Polyurethane foam is used after welding to encapsulate the components assembled within the housing.

\section{Welding Equipment}

This project utilized a $60 \mathrm{kV}$ high voltage electron beam welding system (Figure 2). This system included a CNC to control the high voltage, beam current, focus current, filament current, beam puddling frequency, beam puddle size, travel speed, and direction. All welding was done at a vacuum level of $1 * 10^{-4}$ torr or better.

Beam puddling was used throughout this project to enable the electron beam to oscillate in a circular motion at a predetermined frequency and diameter. This technique is especially beneficial in reducing centerline hot cracking in the weld metal when autogenously electron beam welding 6061 aluminum. The oscillating action stirs the molten metal and equally distributes the silicon content throughout the weld pool. This stirring action has the added benefit of working gases and contaminants out of the molten 


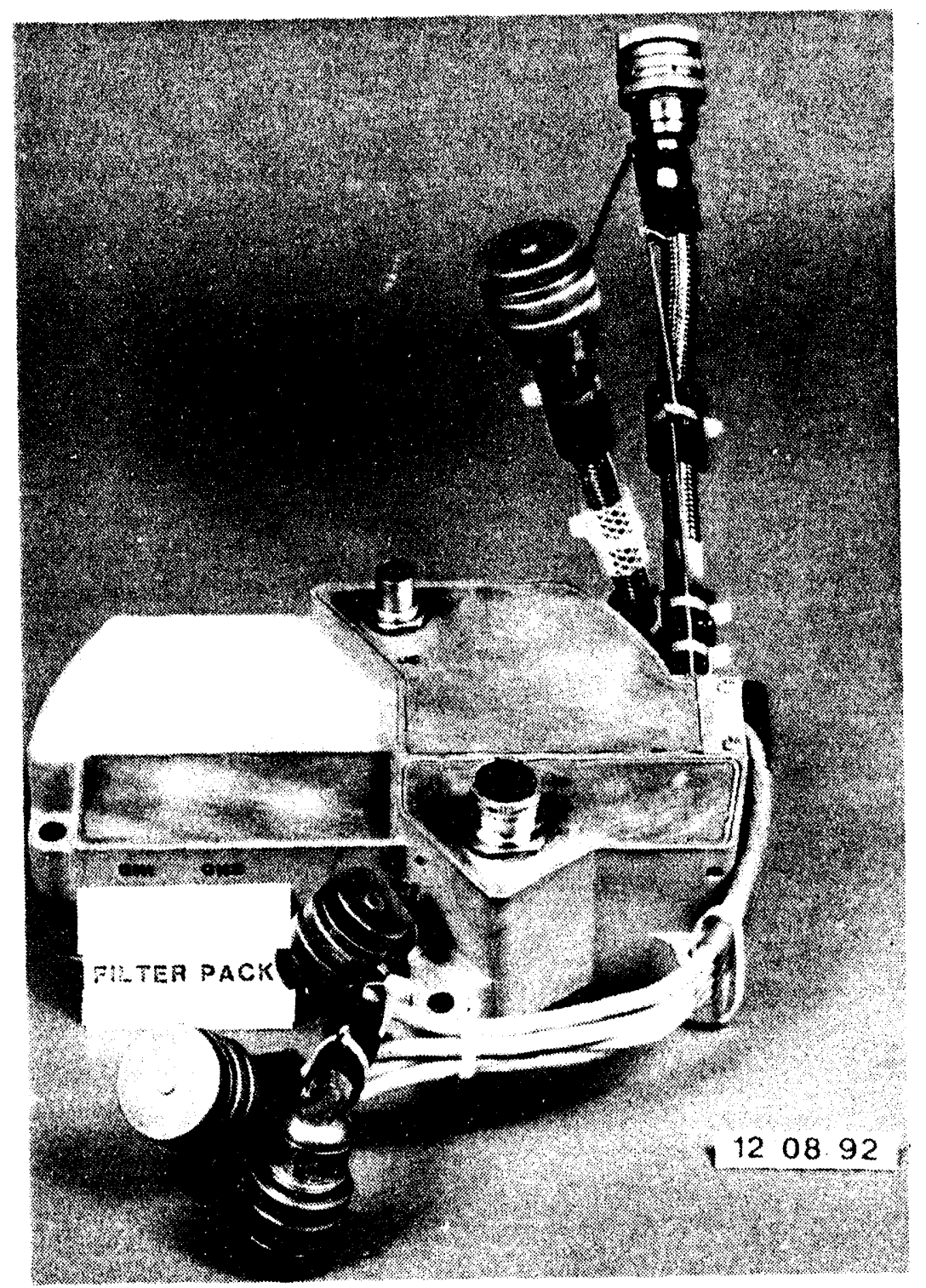

\section{Figure 1. The Filter Pack Assembly}

weld metal which in turn minimizes weld metal porosity.

\section{Penetration Study}

Previous electron beam development efforts on an earlier Filter Pack Assembly 1 served as a basis for weld development on this Filter Pack Assembly. The development used both a closed square butt joint and a closed lapped corner joint (Figures 3 and 4 ).

The assembly was redesigned to incorporate only the closed square butt joint design for all four covers. The main weld requirement on this filter pack assembly is weld penetration. Weld penetration requirements were initially 40 to $60 \%$ of the cover thickness 10.025 to 0.038 in. for the 0.0625 in. thick cover and 0.036 to 0.054 in.for the 0.09 in. thick covers), but was later expanded to 40 to $90 \%(0.025$ to $0.056 \mathrm{in}$. for the $0.0625 \mathrm{in}$. 


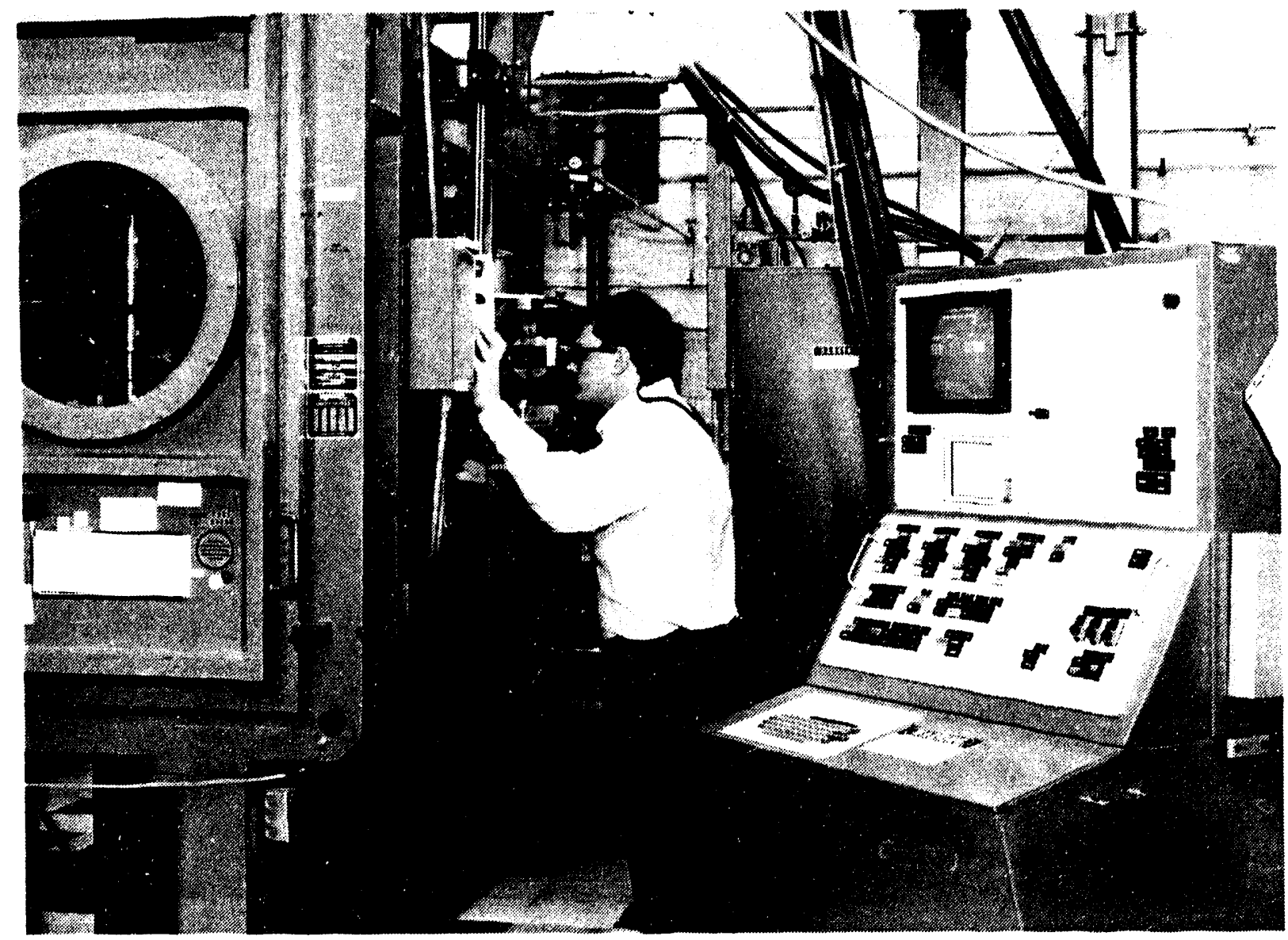

Figure 2. $60 \mathrm{kV}$ High Voltage Electron Beam Welding System

thick cover and 0.036 to $0.081 \mathrm{in}$. for the 0.09 in. thick covers).

Initial developmental efforts began with bead-on-plate welds made on 0.125 in. 6061-T6 aluminum plates. All four cover patterns were welded on the test weldment plate varying only beam current as the controlling factor affecting weld penetration. The remaining weld parameters were held constant: focal length set to 5 in., focus set at sharp, accelerating voltage set to $35 \mathrm{kV}$. puddle size set to 080 , puddle frequency set to $60 \mathrm{~Hz}$, and travel speed set to 48 IPM. The intent of this exercise was to later correlate weld penetration on plate test weldments to predicted weld penetration on cast housings. Target average weld penetrations of 0.058 and $0.040 \mathrm{in}$. were desired for the 0.090 and 0.0625 in. plates, respectively. The four patterns welded on the plate were sectioned in four locations (Figure 5) and weld penetration measured. The results of the bead-on-plate study (Figures 6-9) would indicate that beam current values of $21 \mathrm{~mA}$ for the 0.090 in. cover and $17 \mathrm{~mA}$ for the 0.0625 in. cover are needed to achieve the target weld penetration values. The target penetration values are only averages since weld penetration did increase between the start and ending of the weld. Each of the four weldment covers were welded to a cast weldment varying beam current (Figures 10-15). Table 1 displays the beam currents used on actual cast 


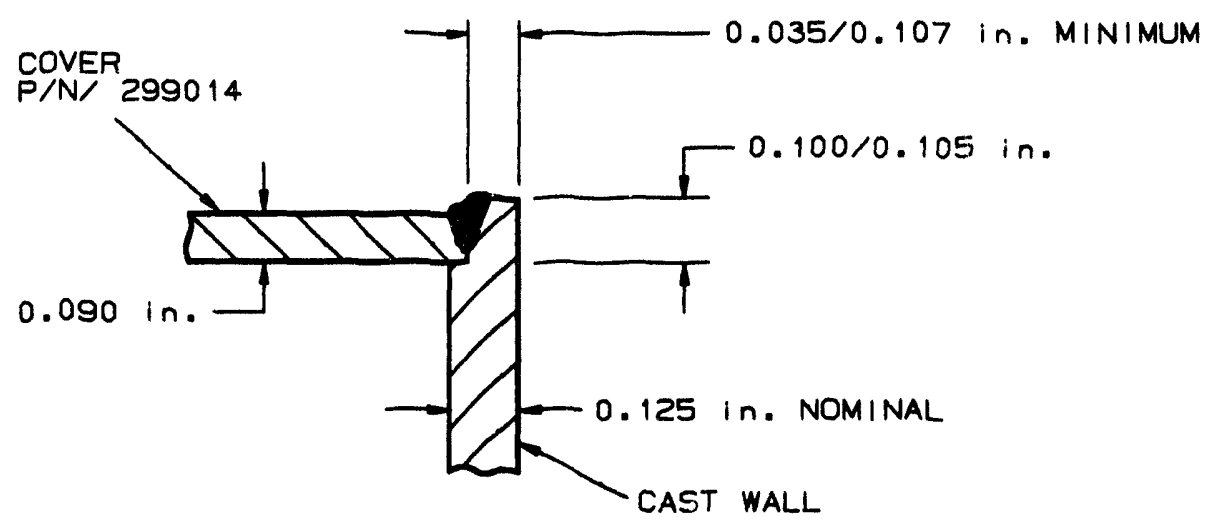

Figure 3. Closed Square Butt Joint on the Input Cover

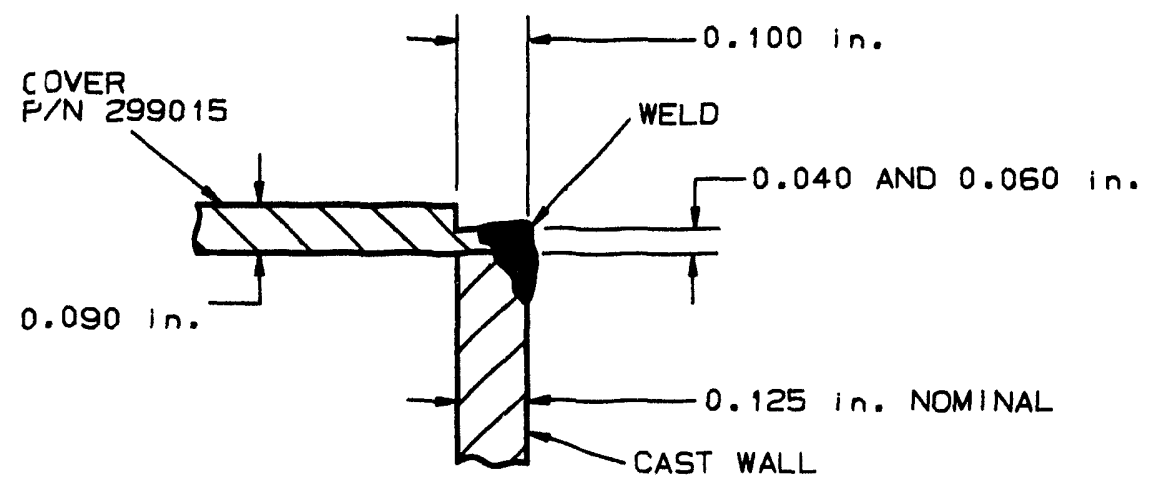

Figure 4. Closed Lapped Corner Joint on the Output

\section{Cover}

weldments and bead-on-plate test weldments and their corresponding weld penetration values. The average weld penetration values may be misleading because weld penetration consistently increased along the weld path. The cast weldments for the same beam current showed an average weld penetration increase of approximately $0.005 \mathrm{in}$. relative to the bead-on-plate values.

The target penetration values for the 0.090 and 0.0625 in. covers would best be reached by using beam currents of 21 and $17 \mathrm{~mA}$, respectively.

\section{Joint Tolerance Study}

The 0.090 in. covers on the Filter Pack subassembly initially required a weld penetration value between 0.036 in. $(40 \%$ cover thickness) to 0.054 in. (60\% cover thickness) throughout the joint tolerance range specified on product drawings. This penetration range would later be expanded to $0.081 \mathrm{in.}(80 \%$ cover thickness). The three electron beam process variables associated with joint tolerances having a significant effect on weld penetration are weld gap, weld mismatch, and beam alignment. Optimum weld conditions would include no weld gap, no weld joint mismatch, and proper beam alignment. These conditions would permit proper heat transfer. The weld joint machined into the A356 cast aluminum housing theoretically could yield a weld gap ranging from 0.000 to 0.009 in. When electron beam welding weldments requiring less than $0.100 \mathrm{in}$. weld penetration, weld gaps should not exceed $0.003 \mathrm{in}$. Welding of wider gaps may require additional heat input, resulting 


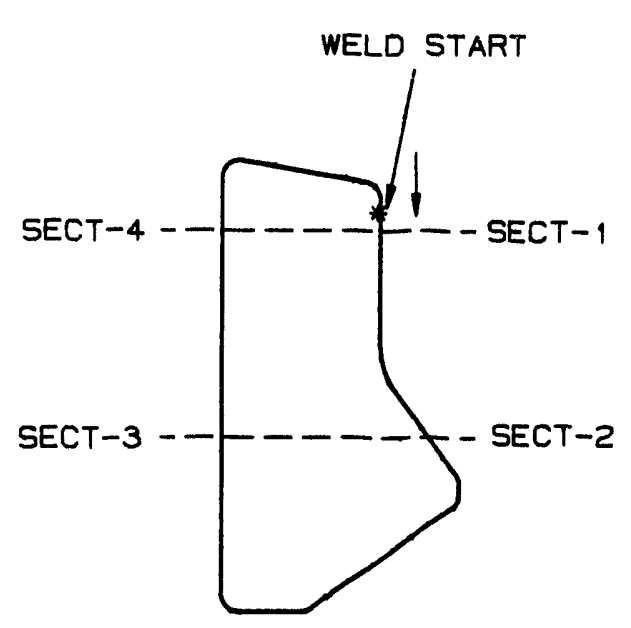

INPUT COVER

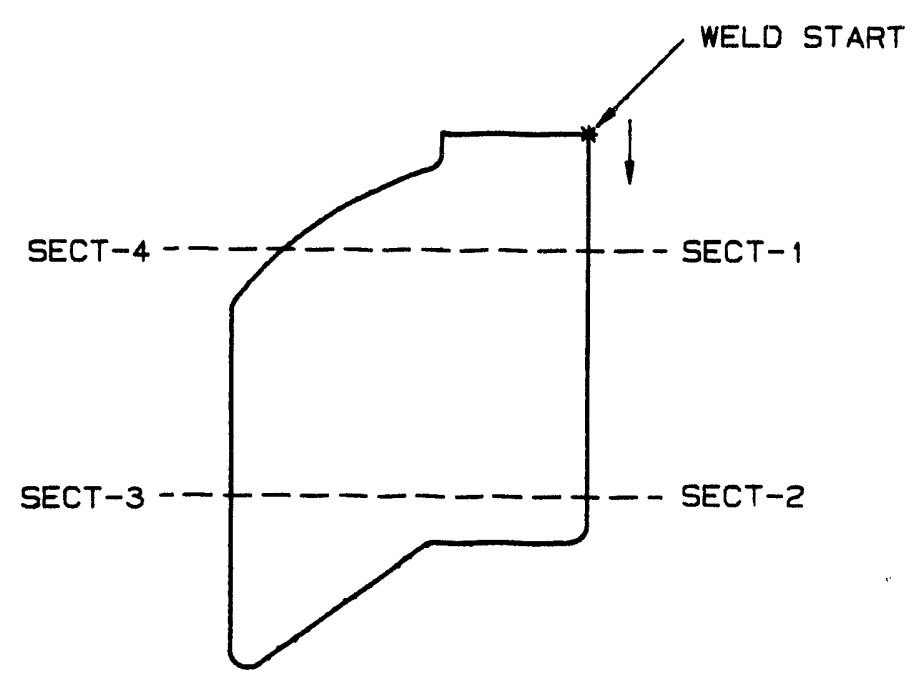

LARGE COVER

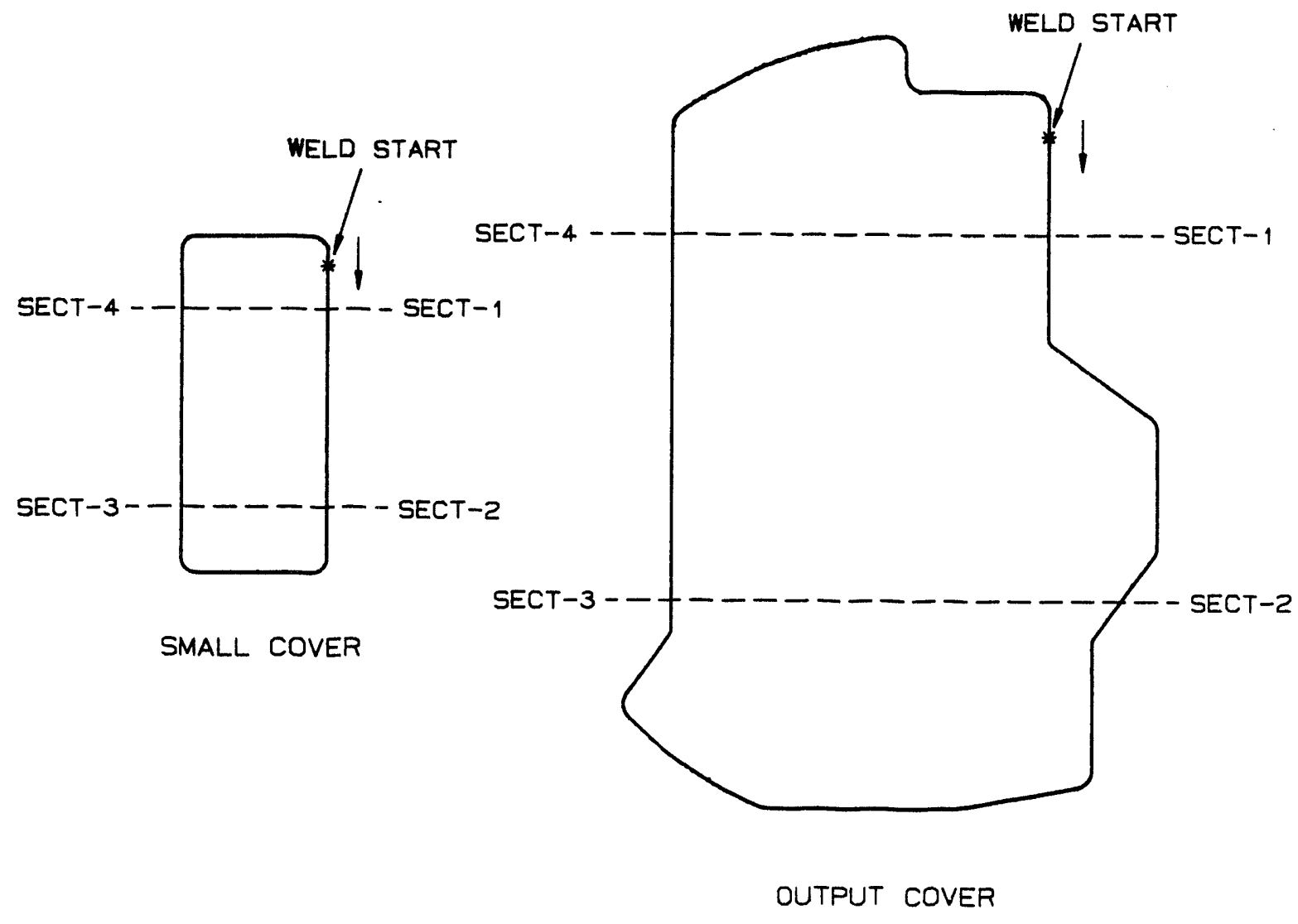

Figure 5. Sectioning Locations on Test Weldment Cover Patterns

in higher weld joint stresses and increased distortion. This study will examine weld gaps as large as $0.010 \mathrm{in.}$ Also, a weld cover mismatch (step) of 0.001 above flush 


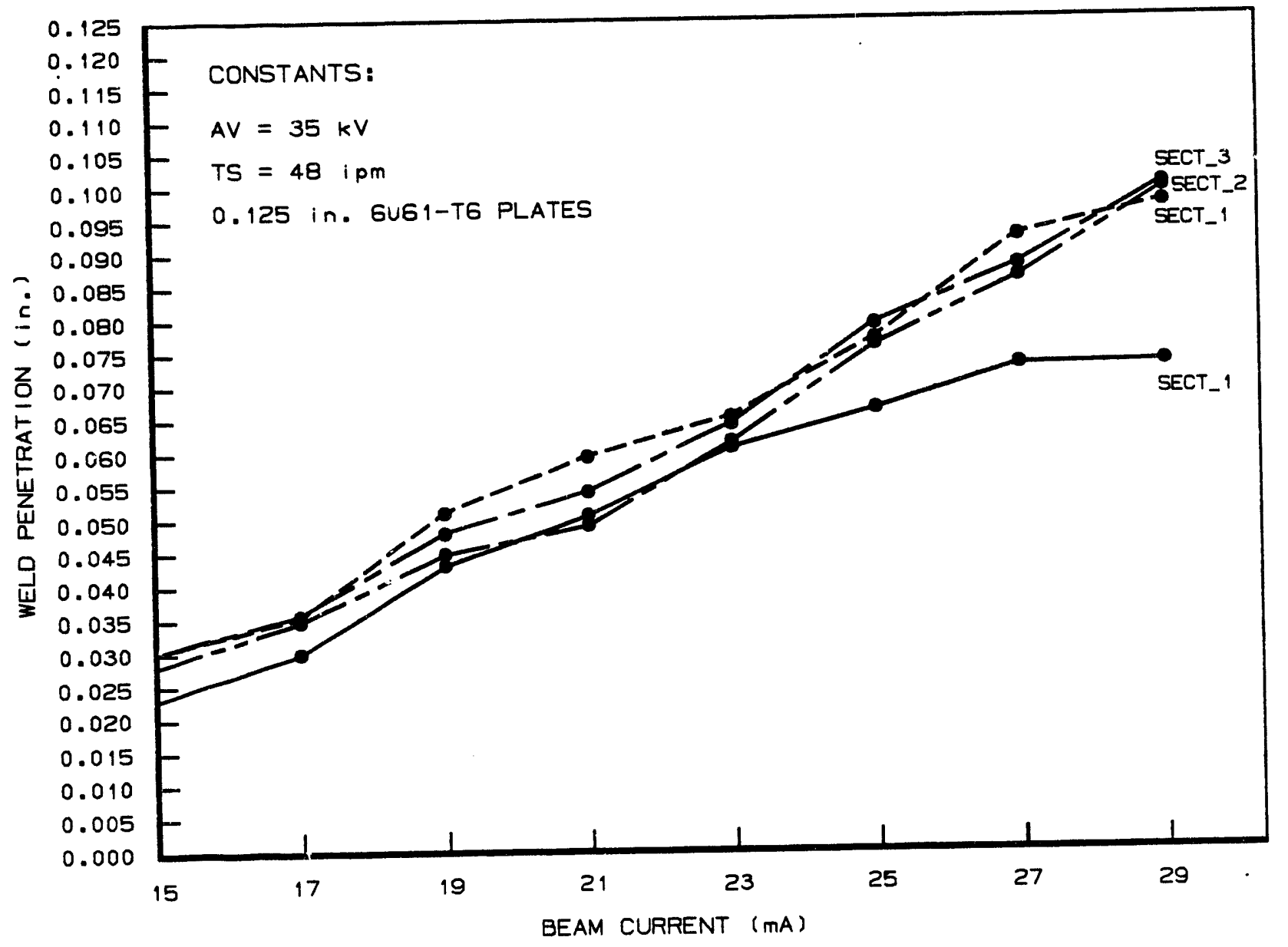

Figure 6. Bead on Test Weldment for Input Cover Pattern

to -0.015 in. below flush is theoretically possible. The dimensional scheme purposely positioned the 6061-T6 aluminum covers near or below flush to ensure proper silicon alloying in the weld pool from the A356 cast housing. Proper silicon content in the weld pool is crucial in preventing centerline hot cracking on 6061-T6 aluminum alloys. Ideally. mismatch should be limited to around 0.003 in. or less. The final significant process variable related to joint tolerance is beam alignment. The welding operator tries to track the beam as best as possible during joint tracking. However, joint tolerances prevent a perfect alignment. Also, it is desirable to slightly favor the A356 casting side of the weld joint (approximately 0.001 to 0.002 in.) to promote good silicon mixing in the weld pool, again to minimize centerline hot cracking in the weld pool. Typical alignment adjustments by the weld operator do not exceed 0.003 in. This characterization will examine the effects of beam alignment as great as 0.006 in.

To better understand how these factors may play a part in affecting weld penetration, a three-factor three-level BoxBehnken statistical study was initiated using a preliminary WPS. The test weldments used for this experiment are shown in Figure 16. It must be noted that these linear test weldments do not account for an increasing heat build-up as welding progresses on actual weldments. This statistical experiment (Table 2) contained 15 randomized welds of various three-level three-variable combinations. 


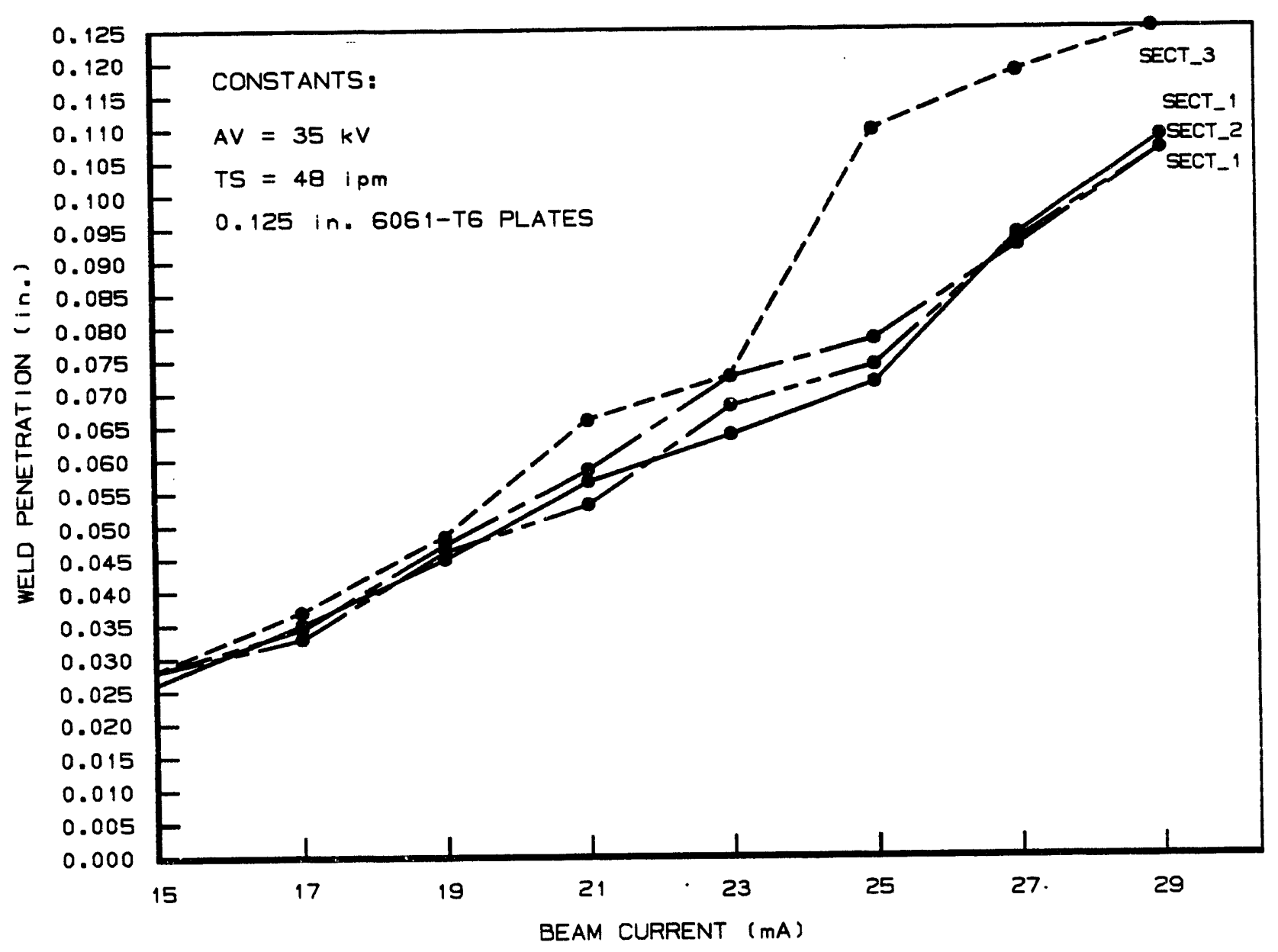

Figure 7. Bead on Test Weldment for Large Cover Pattern

Boundary conditions (Table 3 ) for weld gap and mismatch were determined from joint tolerances specified on the product drawings. The product drawing specifies a weld gap not to exceed 0.006 in. However, up to 0.009 in. gap is allowable for up to $30 \%$ of the total path length except in radius areas. The boundary conditions for beam alignment were determined from maximum weld operator corrections. The weld operator typically does not offset the beam more than 0.003 in. A more severe condition was simulated by extending the beam alignment to 0.006 in. All other significant variables (Table 4) were held constant.

Weld penetration was the only response variable that was recorded and analyzed. However, bead width along with engineering notes were documented. Stepwise regressions were performed on the three independent variables involved in this experiment. Also models representing the functional relationships between the independent variables and weld penetration were found. These models all use standardized values for the independent variables; that is, the variables values were scaled from -1 to 1 (Tables 2 and 3).

The statistical analysis of the data produced the following standardized model, representing the functional relationship between the three parameters involved and weld penetration in inches as shown: 


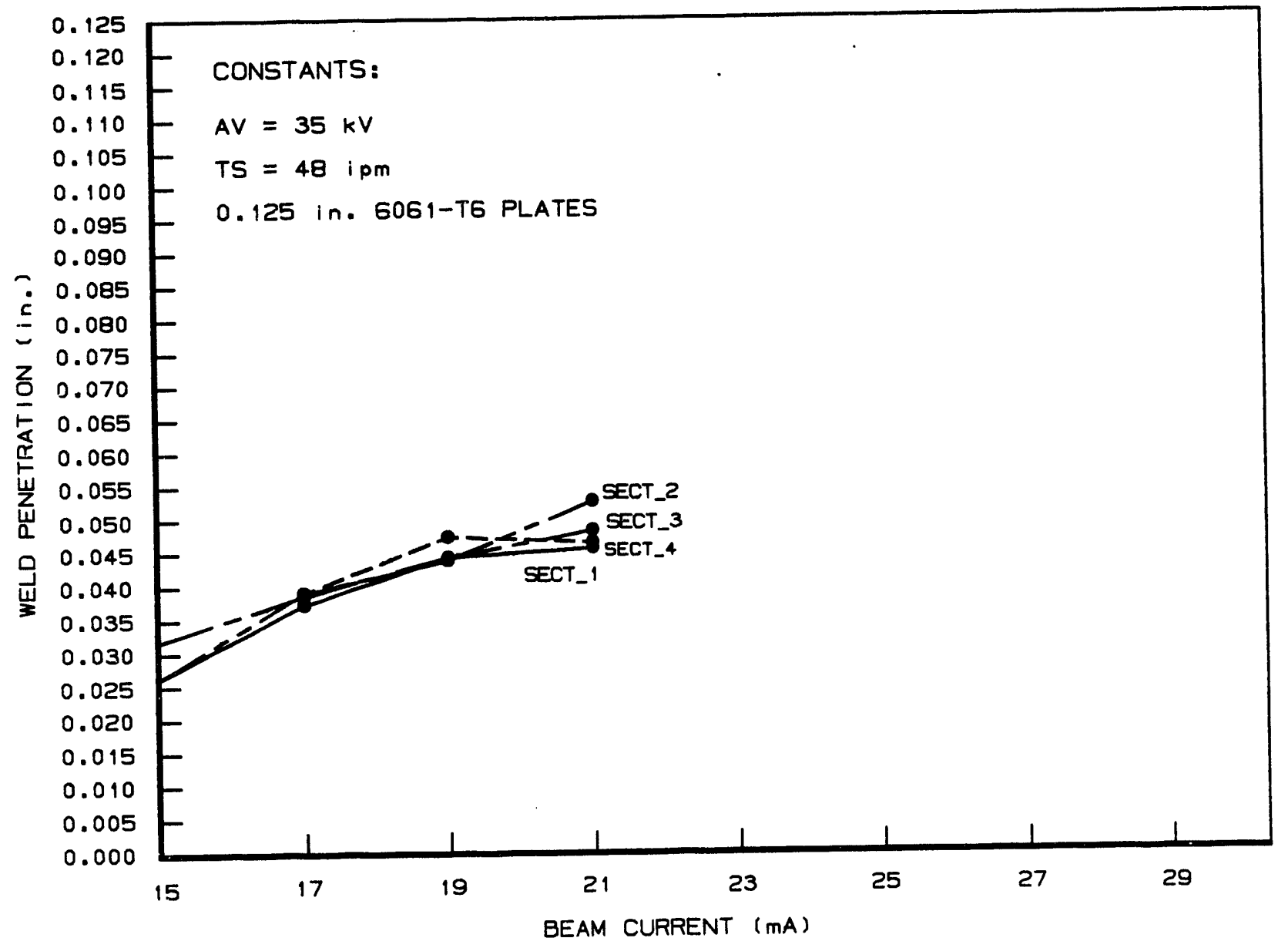

Figure 8. Bead on Test Weldment for Small Cover Pattern

$P=.042-.003($ ALN) $-.003($ GAP) +.004 $(S T E P)^{2}+.004(\text { GAP })^{2} \quad R 2=94 \%$

Model (1).

where $P, A L N, G A P$, and STEP are weld penetration, beam alignment, weld gap, and weld mismatch, respectively. As shown by Model 1, the average penetration obtained was 0.042 in. when all three independent variables are held to their median levels. Both beam alignment and weld gap have a significant effect on weld penetration within the boundary conditions established. When these two parameters were welded at their low levels, weld penetration diminished. Both step and weld gap add a quadratic effect to the model. To maximize weld penetration for the given boundary conditions, beam alignment should be slightly off joint center (also desirable metallurgically with these material combinations) and the weld gap and mismatch should be minimized. The model fit for the data was $94 \%$. A pictorial representation for this model can be seen in three surface response curves shown in Figures 17-19. Similar boundary conditions. were duplicated on actual weldments.

These weldments would better approximate additional factors which may play a significant role in establishing weld penetration, such as heat flow. The design agency opened up the weld penetration requirement from 0.054 in. $(60 \%$ cover thickness) to 0.081 in. ( $80 \%$ cover thickness). Therefore, beam current was increased to $21 \mathrm{~mA}$ on the three $0.090 \mathrm{in}$. covers. Gap sizes of 0.005 and 0.010 in. were machined into the covers at various mismatch levels as shown in Figures 20-23 


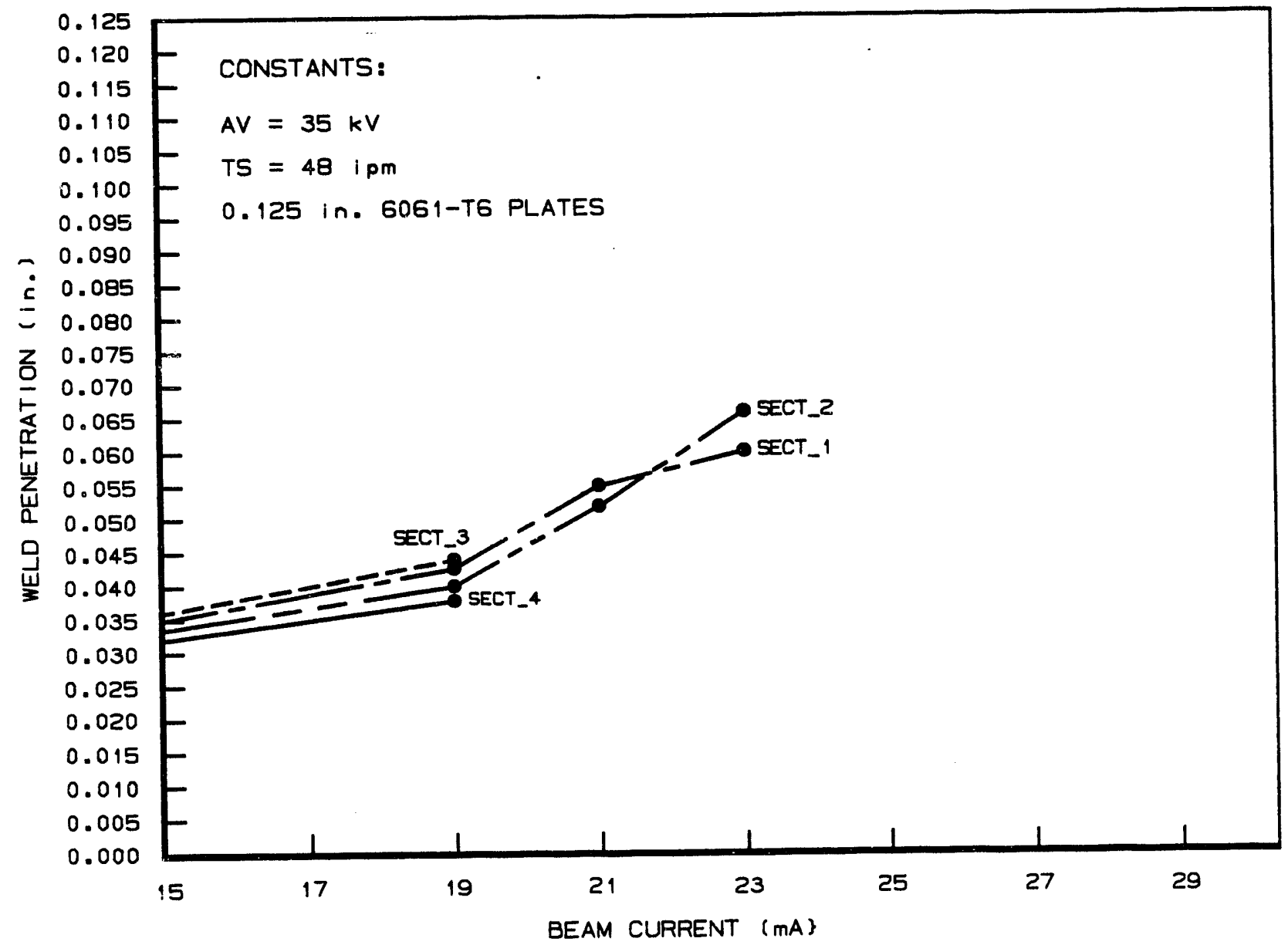

Figure 9. Bead on Test Weldment for Output Cover Pattern

along with their corresponding average weld penetration values.

\section{Weldment Cleaning Study}

Weld joint surface contaminations such as oxides and/or hydrocarbons may cause problems such as weld metal porosity, voids, expulsion and/or cracking. Proper cleaning of aluminum alloys prior to welding is crucial for sound weldments. Aluminum alloys rapidly develop a selflimiting oxide surface when exposed to air. This oxide has a melting point of $1900^{\circ} \mathrm{C}$ which is $1300^{\circ} \mathrm{C}$ higher than aluminum alloys. Particles of this oxide film can be entrapped in the weld metal and impair the weld ductility. Hydrocarbons (from grease and oils) left on the weld surface may result in weld metal porosity which in turn reduces mechanical properties. Aluminum surfaces may also contain a chromate protective surface that provides good corrosion resistance. The chromate coating used on the Filter Pack Assembly is an alodine process consisting of a chromate-phosphate treatment using an acid solution containing chromates. phosphates, and fluorides. The resulting protective coating of approximately 0.01 to 0.02 mil contains chromium and phosphorus as well as aluminum. This coating is found to contain $9.43 \% \mathrm{Al}$, $19.67 \% \mathrm{Cr}, 32.8 \% \mathrm{PO}_{4}$, and $26.1 \% \mathrm{H}_{2} \mathrm{O}$. The high water content in alodine is why good welding practices specify its removal prior to welding. Normal industrial aluminum weld cleaning procedures consist of degreasing with a solvent such as acetone or alcohol to remove hydrocarbons, followed by some 


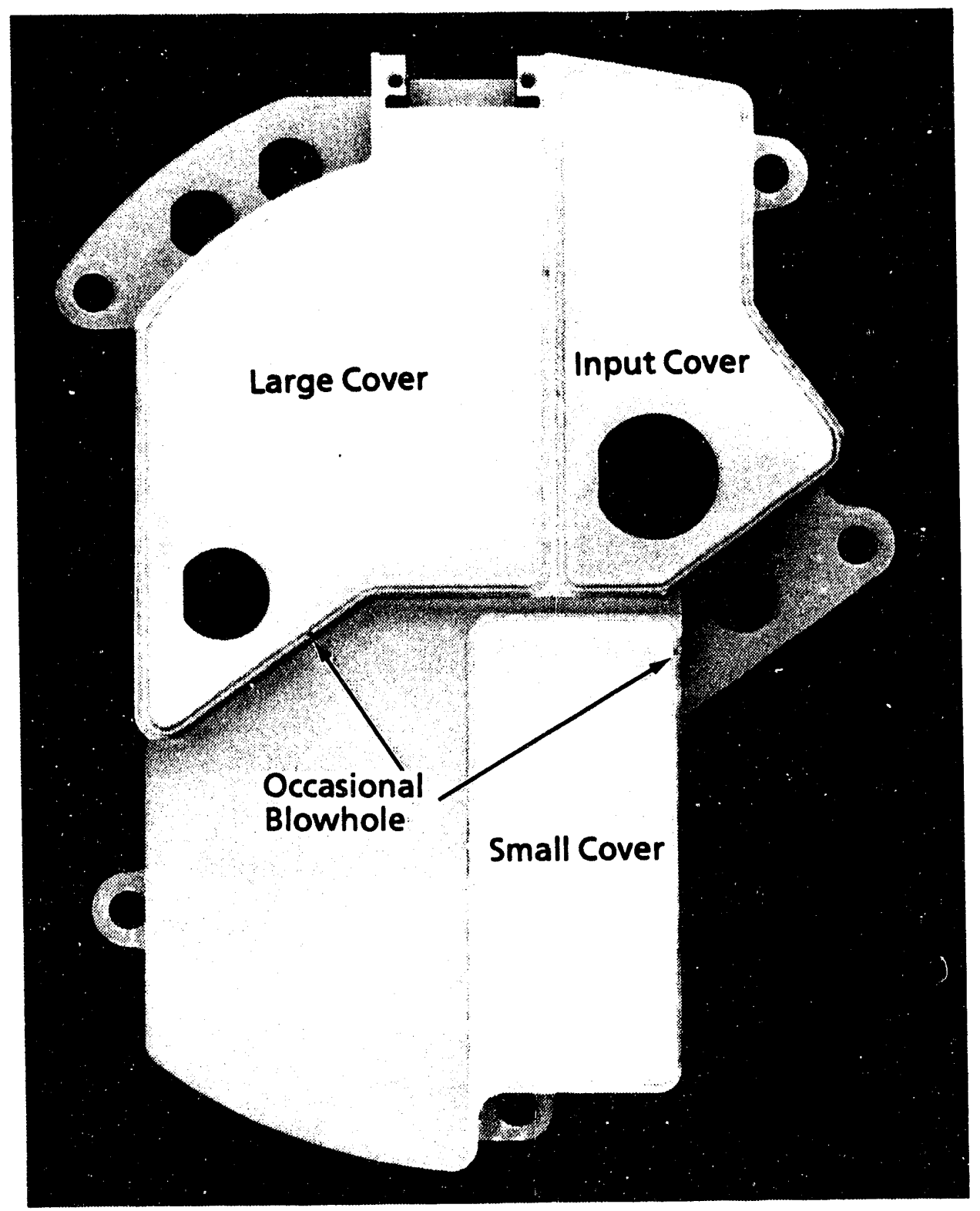

Figure 10. Input, Large and Small Covers Welded to a Cast Weldment

mechanical cleaning (such as scrapping or stainless steel wire brushing) to remove oxides and/or surface coatings. Scraping is considered a better method over wire brushing in the removal of oxides since wire brushing may embed contaminants into the weld surface.
The Filter Pack Assembly design requirements do not permit wire bush cleaning or scraping on the A356 cast aluminum housing. This filter pack housing contains electronic components which may be damaged from conductive particles falling onto the filters from any of these metallic cleaning methods. Wire brush cleaning is permissible on the four covers 


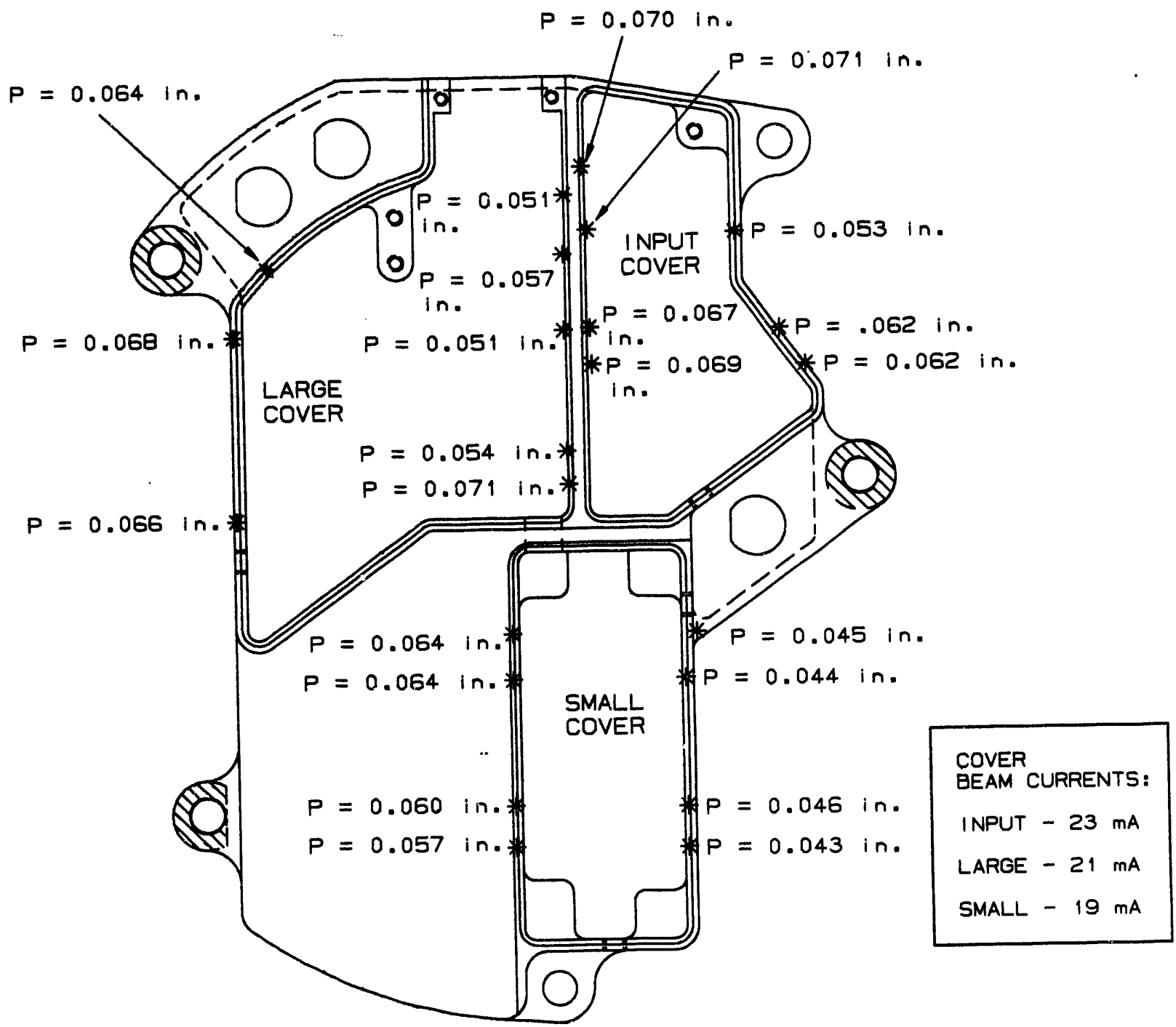

Figure 11. Weld Penetration Values at Various Locations on the Cast Weldment

since they could be cleaned away from the housing. Work at Sandia National

Laboratories 2 suggests that small regions of chromate and oxides left on degreased weld joints prior to electron beam welding will have little degradation of weld quality. Process flow time for welding the Filter Pack Assembly would significantly improve if the alodine surface did not have to be removed.

The first phase of this cleaning study investigated the feasibility of electron beam welding a complete Filter Pack Assembly with the alodine surface left on the weld joint. This condition would not only eliminate particle generation around the electronic components but also reduce cleaning time, improve weldment appearance, and maintain desirable sharp joint edges. A degreased weldment was welded utilizing the latest weld procedure. Weld puddle oscillation was used to agitate the molten weld pool, thereby reducing gas entrapment which reduces weld metal porosity. The results on this first phase of the cleaning study indicate that small regions of chromate left on the weld joint would not greatly diminish weld soundness. However, longer lengths of alodine left on 


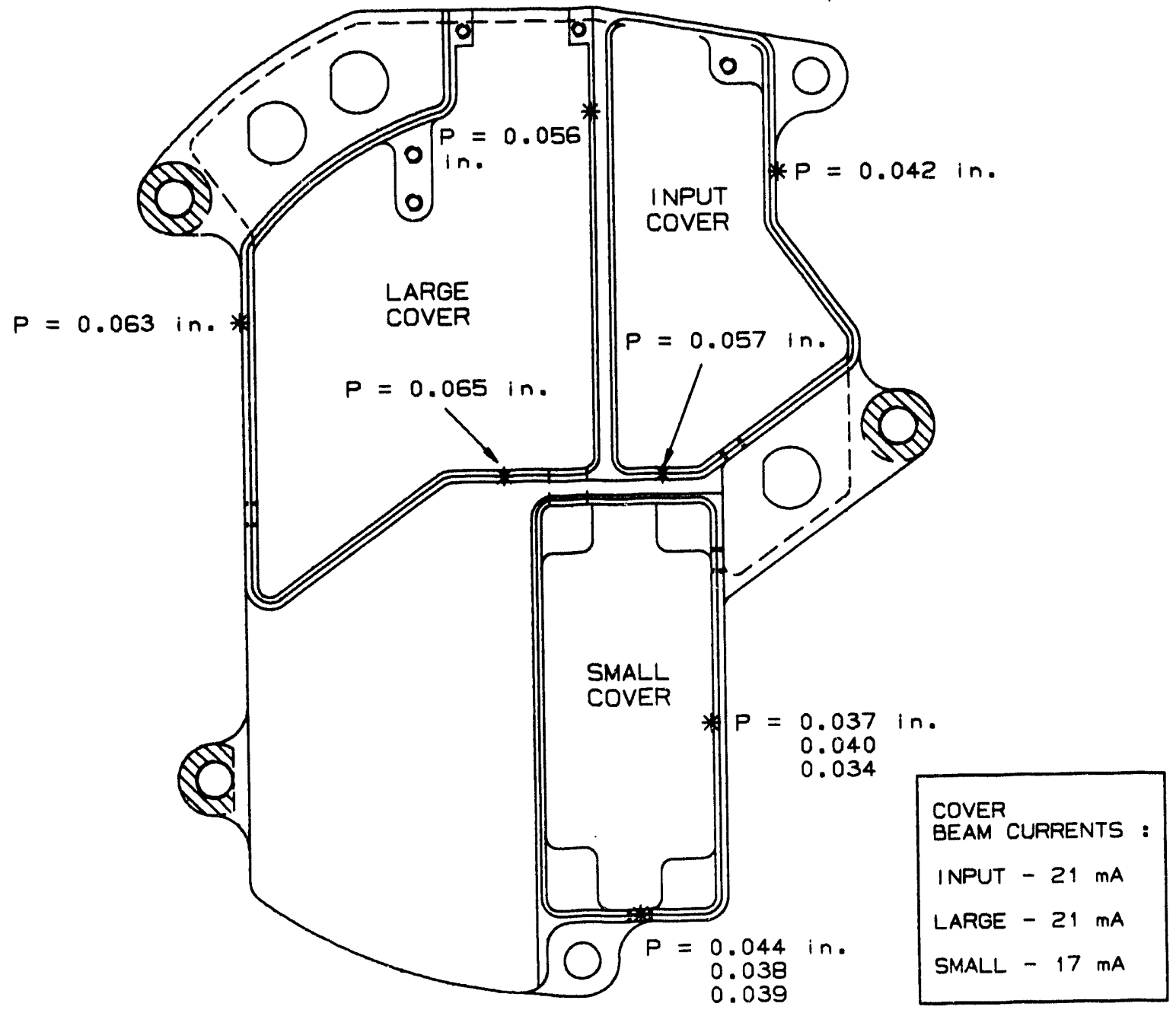

Figure 12. Weld Penetration Values at Various Locations on

the weld joint do seem to increase weld metal porosity.

The second phase of this cleaning study involved the investigation of nonmetallic cleaning methods. A successful nonmetallic cleaning method used in past applications for removing chromate on aluminum was dolomite blasting: a fine stream of calcium magnesium carbonate directed at the weld joint followed by a $10 \%$ acetic acid rinse (removes all traces of residuals). However, acetic acid cleaning was not allowable for this application. Therefore, four alternative nonconductive abrasive materials were investigated: fiber glass, polyester fiber, ink eraser, and pencil eraser.

The first step of phase two of this cleaning evaluation was to examine the chemical composition of each nonconductive abrasive material. This evaluation would be helpful in understanding what types of residual material might be left on the weld surface and what decomposition products would outgas during welding. The chemical composition was determined using FTIR and Direct Probe Analysis. 


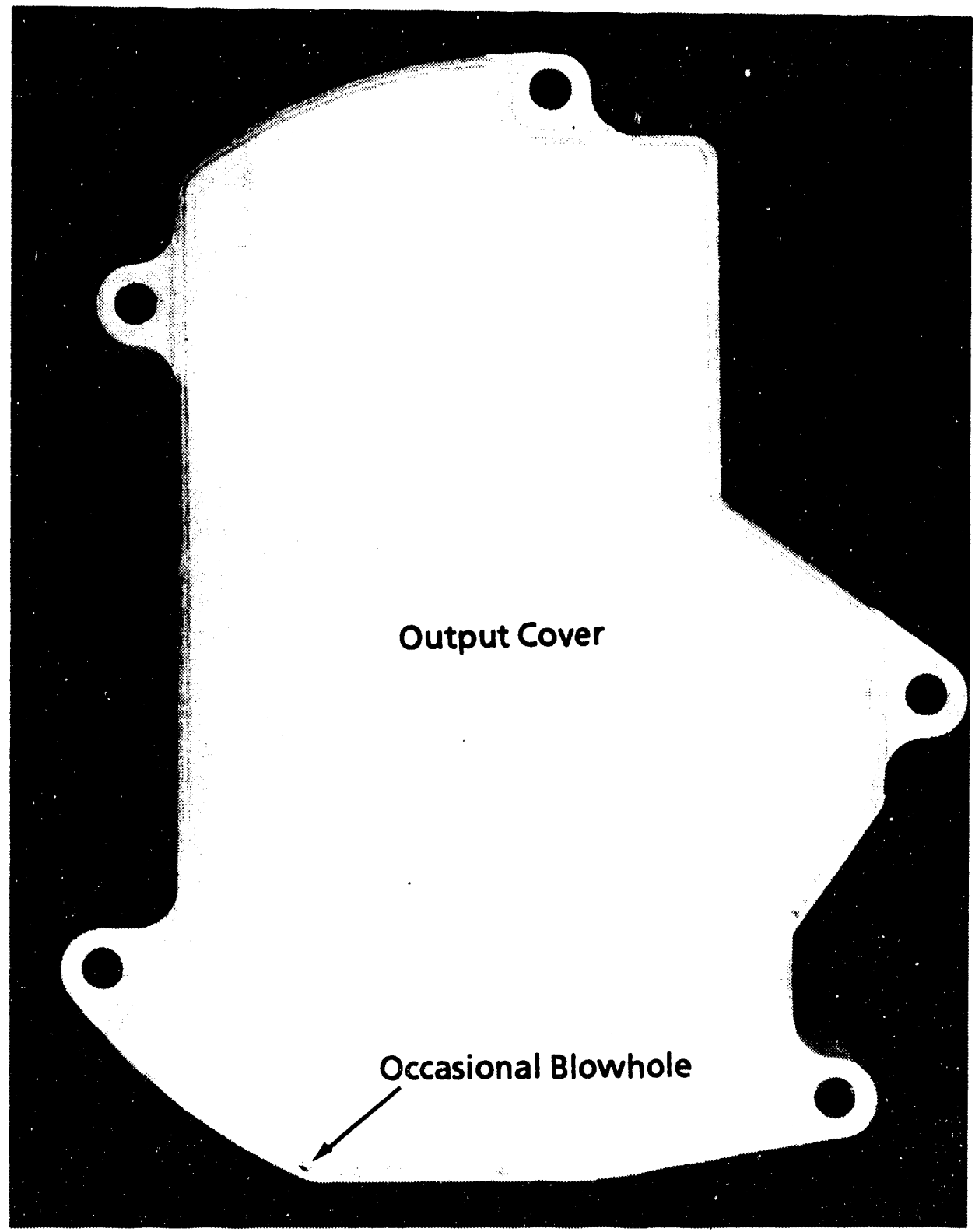

Figure 13. Output Cover Welded to a Cast Weldment

The combination polyester fiber with acrylic adhesive holding the fibers together melts at approximately $256^{\circ} \mathrm{C}$; and principal outgassing would consist of acetaldehyde, $\mathrm{CO}, \mathrm{CO}_{2}, \mathrm{C}_{2} \mathrm{H}_{4}, \mathrm{C}_{6} \mathrm{H}_{6}$, etc.. along with some methyl methacrylate from the acrylic (Figure 24). The pen eraser was basically a hydrocarbon rubber. This material melts at approximately $220^{\circ} \mathrm{C}$. Polyisoprene would outgas isoprene, dipentene, and other unsaturated hydrocarbons

(Figure 25). The pencil type eraser was a polyvinyl chloride rubber that outgasses dioctyl phthalate plasticizer below $350^{\circ} \mathrm{C}$. During decomposition it will outgas hydrogen chloride and unsaturated hydrocarbon (benzene) (Figure 26). Any residual hydrocarbons that were not removed by the weld operator prior to welding would result in weld metal porosity. 


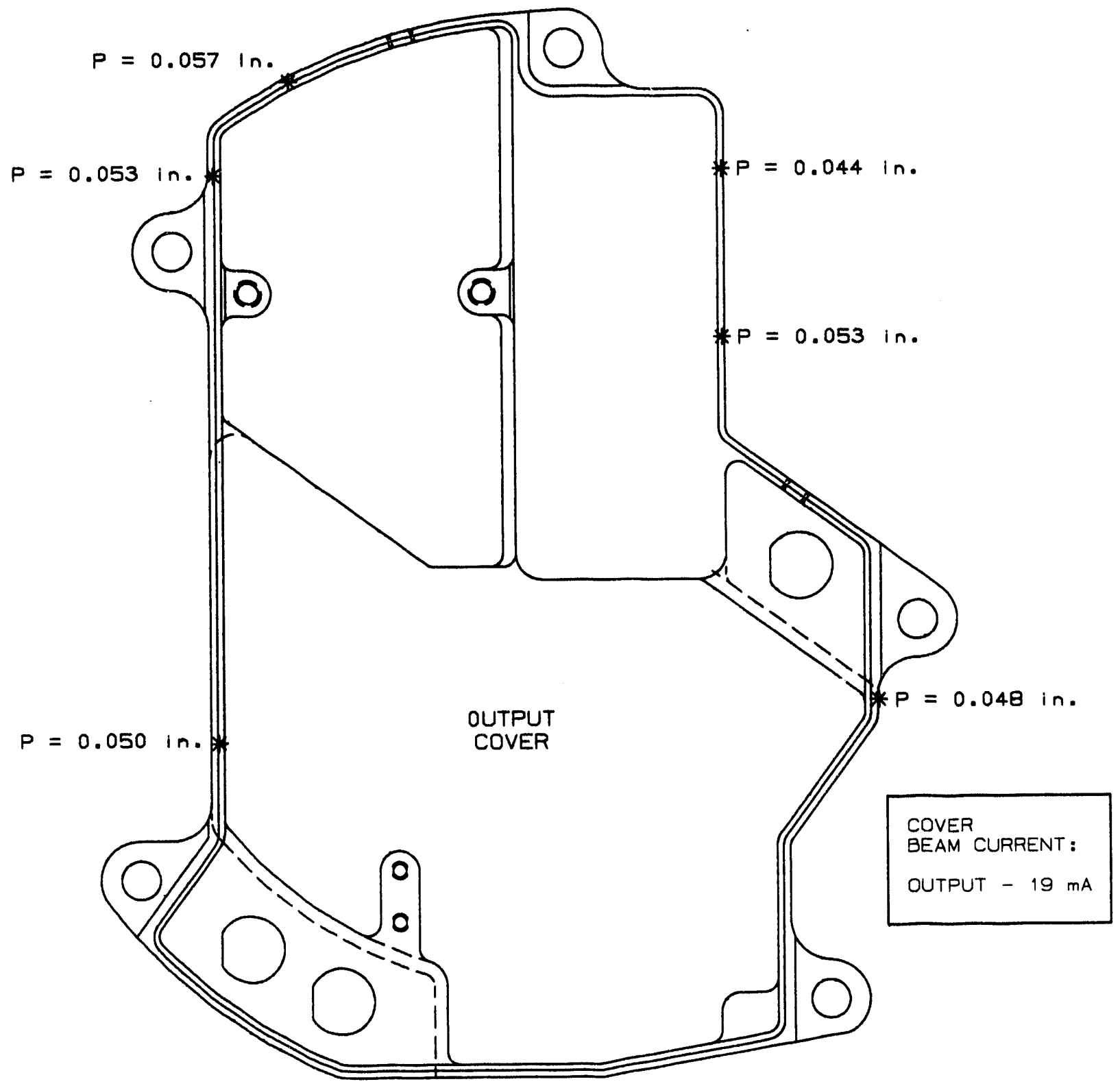

Figure 14. Weld Penetration Values at Various Locations on the Cast Weldment

Therefore, both the ink and pencil eraser materials were too risky to consider as viable alternatives.

The third phase of this cleaning study was to determine the effectiveness of removing alodine coatings by each of the nonconductive cleaning materials and quantify any actual abrasive or metallic particles that may remain on the aluminum surfaces after cleaning. The stainless steel wire brush cleaning method was added to this third phase of the evaluation as a bench mark to compare the other cleaning methods. The various cleaning methods were used on both 6061-T6 aluminum sheet and A356 cast samples using both an alcohol and no alcohol wipe. The no alcohol wipe was added to simulate worst-case condition when an operator may miss wiping down a portion of the weld joint area. The various combinations 


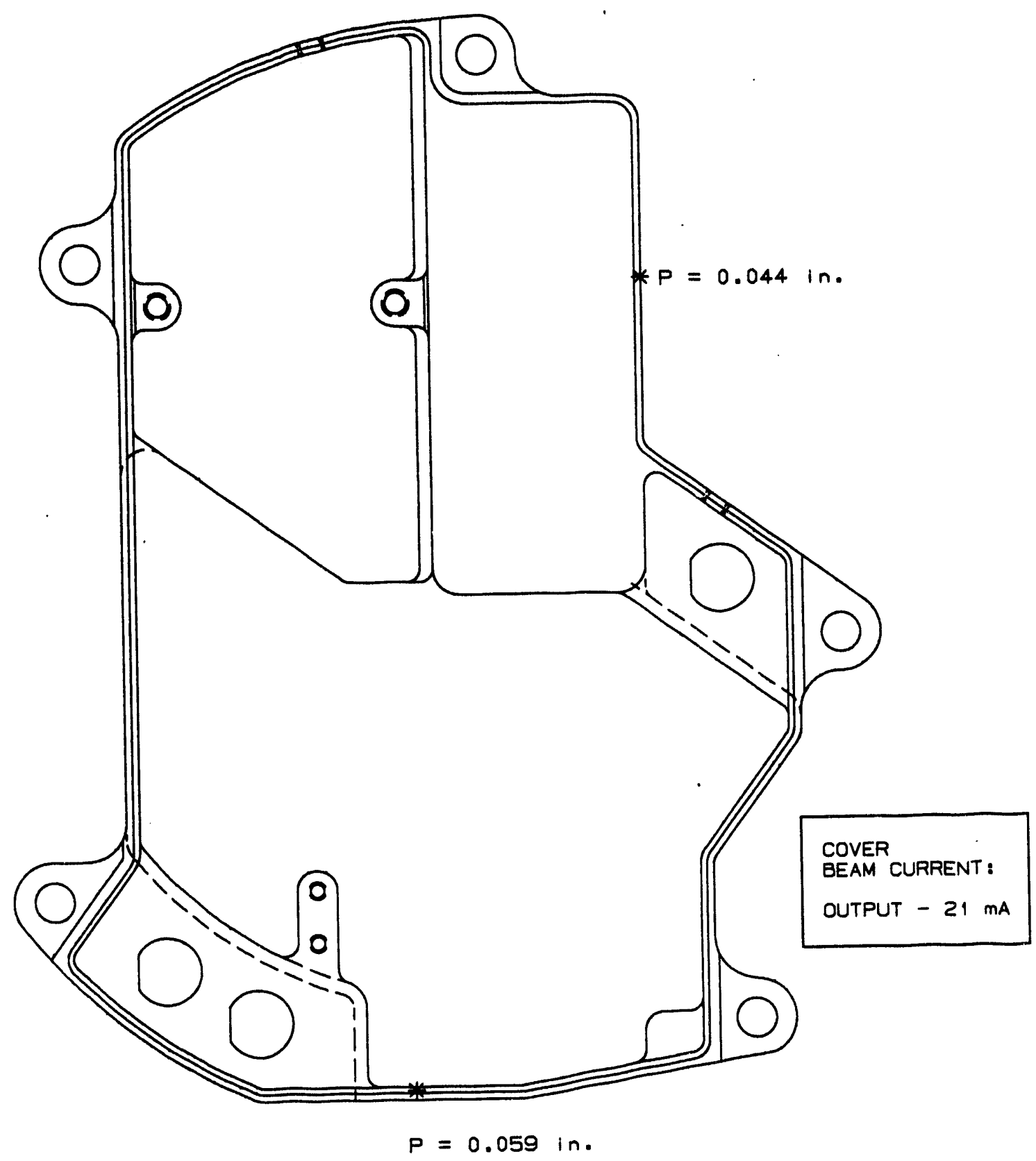

Figure 15. Weld Penetration Values at Varlous Locations on the Cast Weldment

of cleaned surfaces were individually ultrasonically cleaned with methylene chloride and this solvent was allowed to evaporate and its residue analyzed using direct probe mass spectrometry. The analysis results indicated that the cast surfaces on the whole collected greater amounts of residue abrasive relative to the 6061-T6 sheet material. The most desirable cleaning method was stainless steel wire brushing which left no detectable solid residue. The fiber glass cleaning method left copious fibers but was still the second most desirable choice (the fiber glass cleaning method had the disadvantage of causing skin irritations to the operator). Both eraser methods left various amounts of eraser residue. The ink eraser left not quite as much as the pencil eraser. In addition, the ink eraser was more abrasive and did a better job of removing the chromate surface. The 
Table 1. Beam Current Variance on Cast Weldment

\begin{tabular}{cccccccc} 
& $\begin{array}{c}\text { Input } \\
\text { Cover }\end{array}$ & $\begin{array}{c}\text { Large } \\
\text { Cover }\end{array}$ & Input & Output & $\begin{array}{c}\text { Output } \\
\text { Cover }\end{array}$ & $\begin{array}{c}\text { Small } \\
\text { Cover }\end{array}$ & $\begin{array}{c}\text { Small } \\
\text { Cover }\end{array}$ \\
\hline BC (mA) & 23 & 21 & 21 & 21 & 19 & 19 & 17 \\
$\begin{array}{c}\text { (Avg. Pen) } \\
\text { casting }\end{array}$ & 0.066 & 0.060 & 0.050 & 0.052 & 0.051 & 0.053 & 0.040 \\
$\begin{array}{c}\text { (Avg. Pen) } \\
\text { plate }\end{array}$ & 0.062 & 0.058 & 0.054 & 0.054 & 0.042 & 0.046 & 0.039 \\
$\begin{array}{c}\text { Change in } \\
\text { Pen }\end{array}$ & 0.004 & 0.002 & -0.004 & -0.002 & 0.009 & 0.007 & 0.001 \\
$\begin{array}{c}\text { (Dimensions are in inches) } \\
\text { Dimensions }\end{array}$ & & & & &
\end{tabular}

polyester fiber cleaning method left the most solid residue and was not an effective chromate removal cleaning method.

\section{Temperature Study}

The Filter Pack assembly contains several heat sensitive components. Excessive heating of the filter pack assembly during welding may cause electrical test failures. The mode of failure would more than likely be melting of solder joints, insulation, or plastic materials causing an electrical continuity failure or insulation resistance failure. The maximum recommended peak temperature exposure for some of these materials and components are listed in Table 5.

Previous welding utilized the manual gas tungsten arc welding process on 6061-T6 aluminum covers to $A 356$ cast housing. The weld procedure specified using small weld lengths of less than $5 / 8$ in. followed by compressed air cooling. The next weld segment would not be welded until the unit was cooled to approximately room temperature. A peak temperature evaluation was conducted for this manual process. Thermocouples were attached at locations which would represent worst case conditions. Peak temperatures were observed and recorded as shown in
Table 6. Historically, no GTA weld damage to components has been observed.

The mechanized electron beam welding process was substituted for the manual gas tungsten arc welding process. Preliminary development work 1 documented how this mechanized welding process could successfully continuously weld the 6061-T6 aluminum covers to the A356-T6 cast aluminum machined housing for the Filter Pack Assembly. Not only does this mechanized high energy density electron beam welding process save considerable processing time but also theoretically should minimize heat input for comparable welds. A temperature study was conducted to document the temperature exposure of the filter pack casting at several specified locations (Figure 27). Thermocouples were attached to several filter mounting locations which would represent worst case conditions. These locations were similar to those locations on the earlier filter pack temperature study for the manual gas tungsten arc welding process. A qualified weld procedure specification (WPS) was used during the temperature evaluation. The continuous electron beam welding process resulted in significantly lower peak temperatures (see TC1 values in Table 6) 


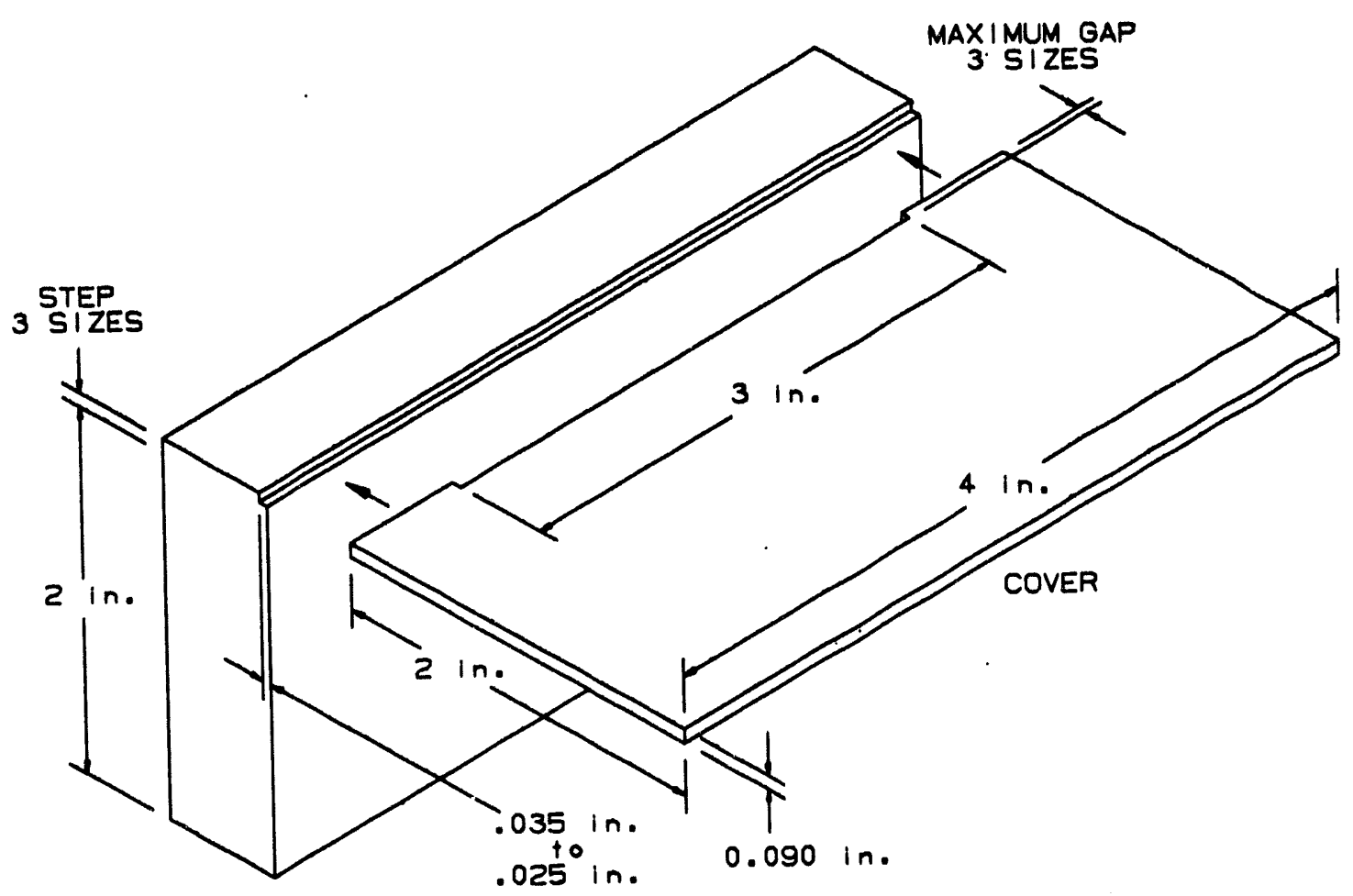

Figure 16. Test Weldment Used In the Joint Tolerance Study

around the input connector, relative to the one $5 / 8$ in. weld segment manually made with the GTA process. The electrical filters experienced no significant temperature variation (TC4, TC5 and TC6) between the two weld processes.

Electron beam welding aluminum alloys occasionally results in blow holes (through porosity). Sometimes these nonacceptable type defects can be electron beam repaired if relatively small, but usually the manual GTAW process is necessary. The welding specification on the Filter Pack Assembly allows for manual GTAW repair of weld defects. A typical blow hole weld repair takes approximately 5 to $7 \mathrm{~s}$ to close. Peak temperature exposure values for 7,15 , and $30 \mathrm{~s}$ of manual GTA weld time were documented (Table 7). The same thermocouple locations on the input cover were used. Two separate weld repair locations were evaluated on the input cover (Figure 27). The resulting temperature values can be seen in
Table 7. No significant temperature concerns occur when weld repairs are under $15 \mathrm{~s}$.

\section{Optical Viewing System Upgrade}

The $60 \mathrm{kV}$ high voltage electron beam viewing system (Figure 28) consisted of two separate assemblies: an externally mounted telescope and an internally mounted base assembly. This base assembly included a reflective mirror, a projection lens, and a rectile cross hair lens. The weld joint image is picked up by the reflective mirror and directed into the projection lens. This lens projects the reflected image through its lens arrangement onto adjustable cross hairs at the rear of the final lens. The weld operator views the projected image externally through the telescope assembly. Several drawbacks to this viewing package included poor viewing of the weld joint and both focus adjustments and cross-hair adjustments being made inside the weld 
chamber. These viewing disadvantages may further increase process flow time and weld rework. Enhanced viewing would aid the weld operator in joint tracking. Joint tracking is especially important in checking to see if the cast side of the weld joint is favored, providing a better silicon mix in the weld metal. A purchased solid state CCD color camera package with remote focus, filtering, and iris adjustments was retrofitted onto the unit's gun along with a mini-Halogen light source for joint tracking (Figure 29). A viewing monitor, cross-hair generator, and camera adjustment panel was inserted into the control cabinet (Figure 30).

\section{Recommendations}

The alodine coating on the weldments should be removed from the weld areas. Small amounts of this alodine coating left in difficult to reach areas (such as weld corners) should not significantly impact weld quality. The preferred alodine removal method is wire brushing followed by an alcohol wipe. This method is permissible on the four covers when done away from the static sensitive components inside the cast weldment. Fiber glass brushing followed by vacuuming of loose particles and then an alcohol wipe is the preferred nonmetallic cleaning method for removing the alodine coating on cast weldments.

\section{Accomplishments}

It was determined that electron beam welding can successfully meet drawing requirements for the Filter Pack Assembly. The heat induced by continuously welding each of the four covers is significantly less than the heat induced from the manual gas tungsten arc welding process. Fiber glass brushing was successfully evaluated as a nonmetallic cleaning method for thoroughly removing alodine from the weld joint area and not diminishing weld quality. Finally, a
Table 2. Three-Variable Three-Level Box-Behnken Statistical Matrix Used to Characterize Joint Tolerance

\begin{tabular}{cccc} 
Run & $\begin{array}{c}\text { Gap } \\
\text { (in.) }\end{array}$ & $\begin{array}{c}\text { Step } \\
\text { (in.) }\end{array}$ & $\begin{array}{c}\text { Align } \\
\text { (in.) }\end{array}$ \\
\hline 1 & 0 & 0 & 0 \\
2 & -1 & -1 & 0 \\
3 & 1 & -1 & 0 \\
4 & -1 & 1 & 0 \\
5 & 1 & 1 & 0 \\
6 & -1 & 0 & -1 \\
7 & 1 & 0 & -1 \\
8 & 0 & 0 & 0 \\
9 & -1 & 0 & 1 \\
10 & 1 & 0 & 1 \\
11 & 0 & -1 & -1 \\
12 & 0 & 1 & -1 \\
13 & 0 & -1 & 1 \\
14 & 0 & 1 & 1 \\
15 & 0 & 0 & 0
\end{tabular}

Table 3. Level Definitions for the Three-Variable Statistical Study on Joint Tolerance

\begin{tabular}{cccc} 
Level & $\begin{array}{c}\text { Gap } \\
\text { (in.) }\end{array}$ & $\begin{array}{c}\text { Step } \\
\text { (in.) }\end{array}$ & $\begin{array}{c}\text { Align } \\
\text { (in.) }\end{array}$ \\
\hline+1 & 0.010 & 0.001 & 0.006 \\
0 & 0.005 & $0-.007$ & 0.003 \\
-1 & 0 & $0-.015$ & 0
\end{tabular}

miniaturized camera system was successfully installed on the electron beam 
Table 4. Electron Beam Weld Variable Identification

Process Variable Setting

Accelerating Voltage (AV) $35 \mathrm{kV}$

Beam Current (BC) $\quad 19$ or $21 \mathrm{~mA}$

Filament Current (FC) $\quad 7.84 \mathrm{~A}$

Beam Focus Current (BF) $\quad 5.15 \mathrm{~A}$

Gun Distance 5 in.

Puddle Frequency $\quad 60 \mathrm{~Hz}$

Puddle Size (XSF\& YSF) $\quad 80$

Focus True

Travel Speed (TS) $\quad \mathbf{4 8} \mathrm{ipm}$

welding system to further aid the weld operator in joint tracking.

Future Work

A near term action item involved the evaluation of a redesigned large cover adapter plate. The current large cover design has a discontinuous weld path along the adapter plate. Epoxy is used to seal the area between the unwelded large cover and the 6061-T6 adapter plate. A redesigned 4043 or 4047 aluminum adapter plate with a machined weld joint will allow for a continuous weld pattern and the elimination of the epoxy seal. 


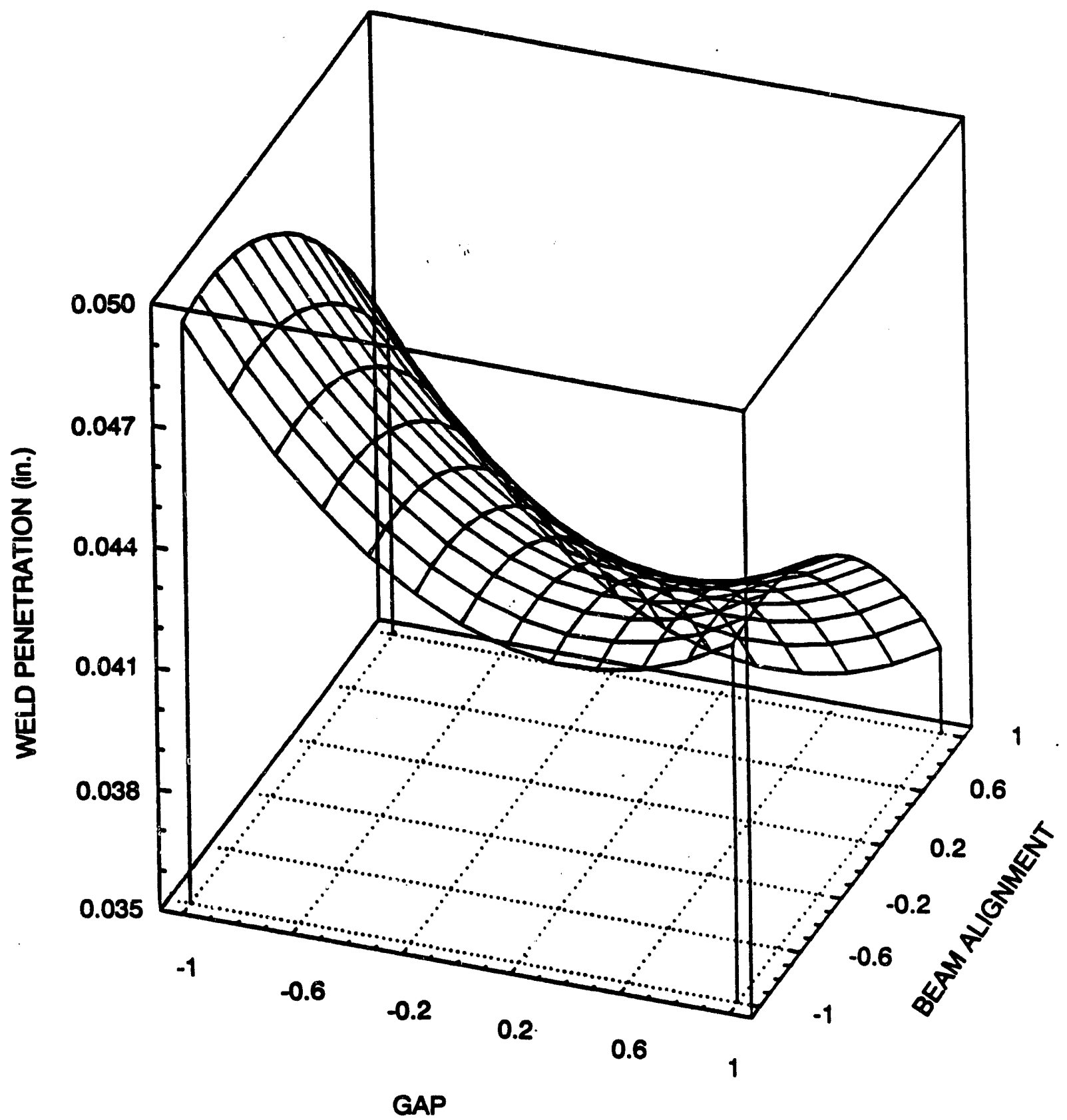

Figure 17. Surface Response Curve Plotting Joint Gap Versus B zam Allgnment 


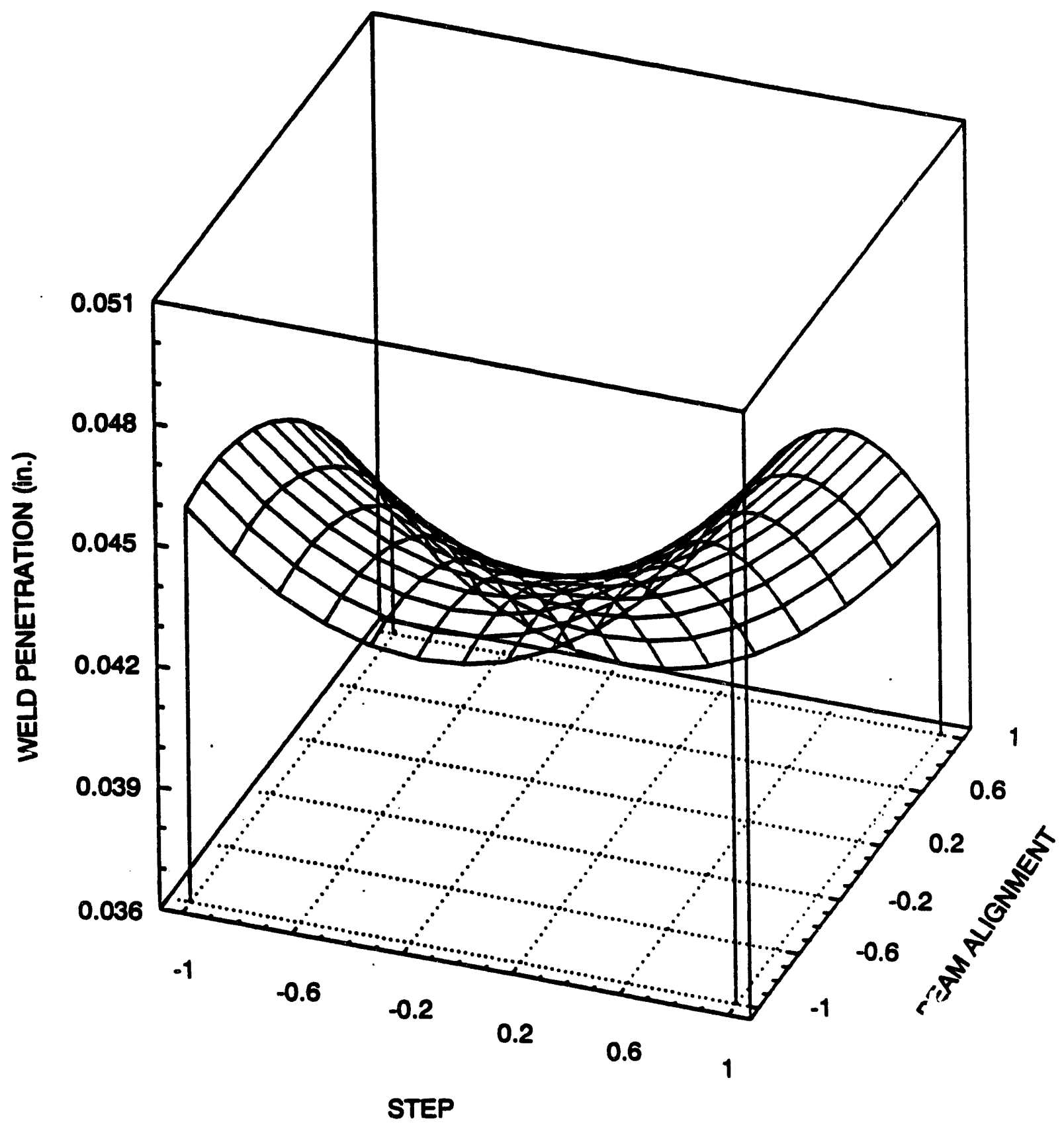

Figure 18. Surface Response Curve Plotting Step Versus Beam Alignment 


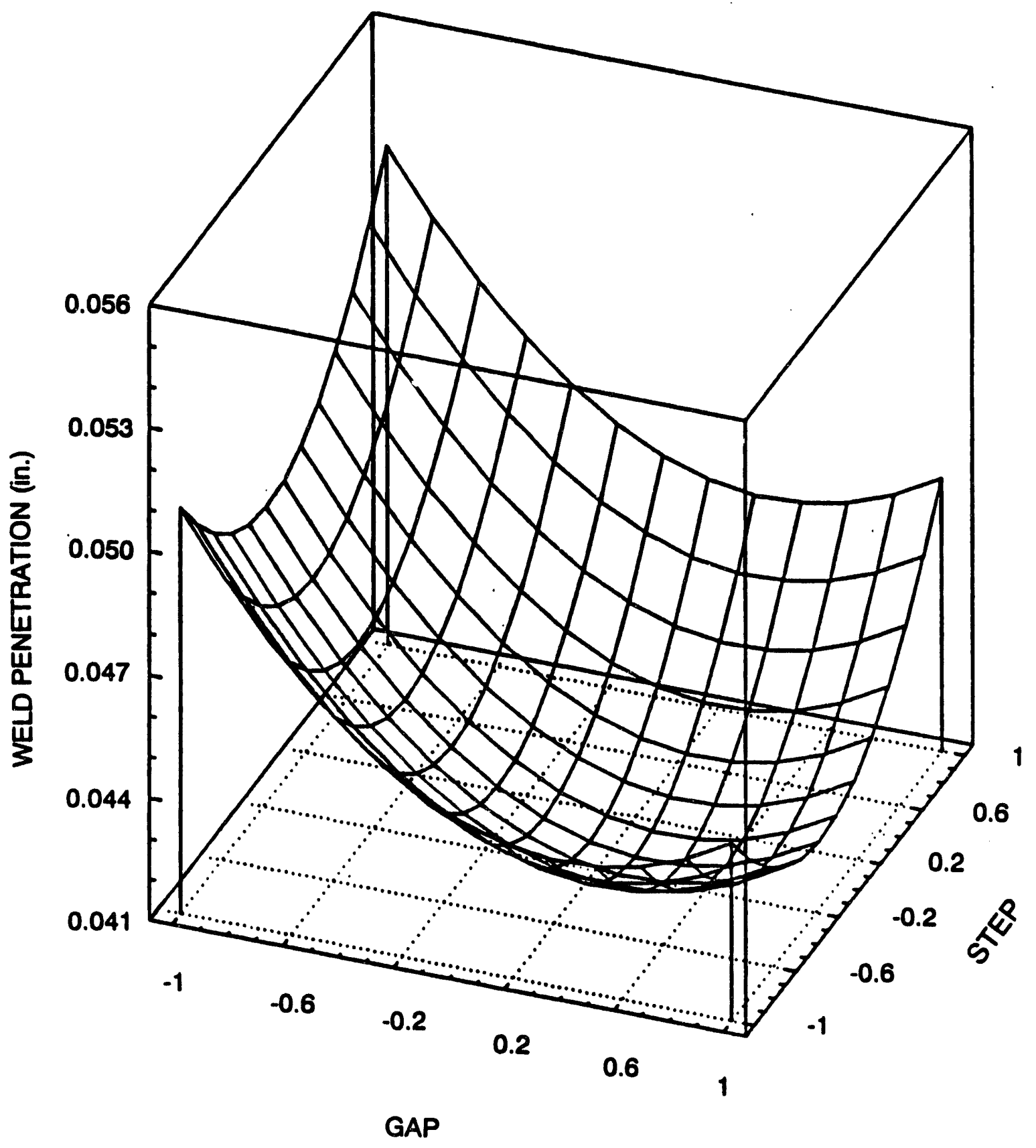

Figure 19. Surface Response Curve Plotting Joint Gap Versus Step 


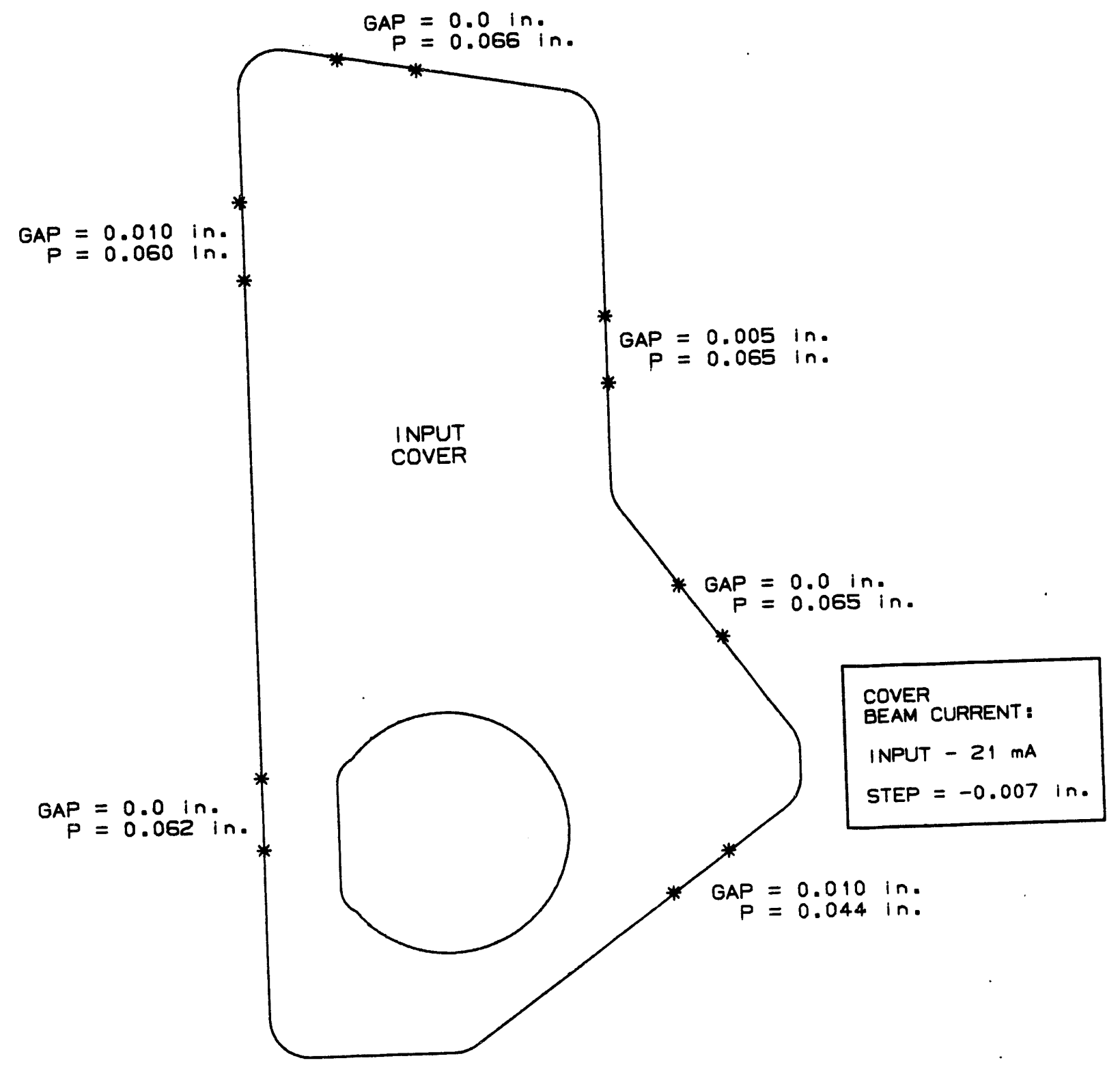

Figure 20. Joint Tolerances Machined Into Cast Weldment for the Input Cover Weld 


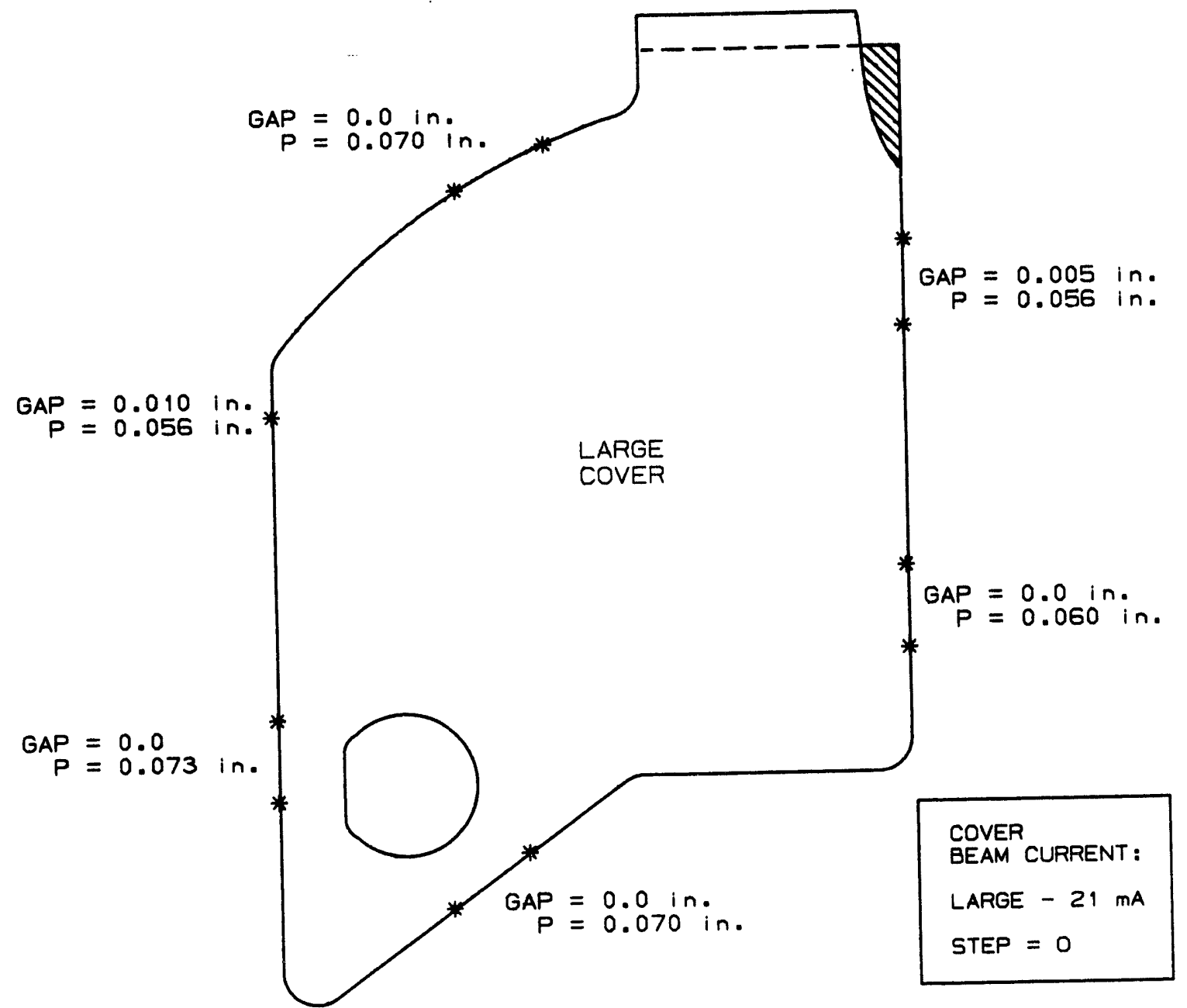

Figure 21. Joint Tolerances Machined Into Cast Weldment for the Large Cover Weld 


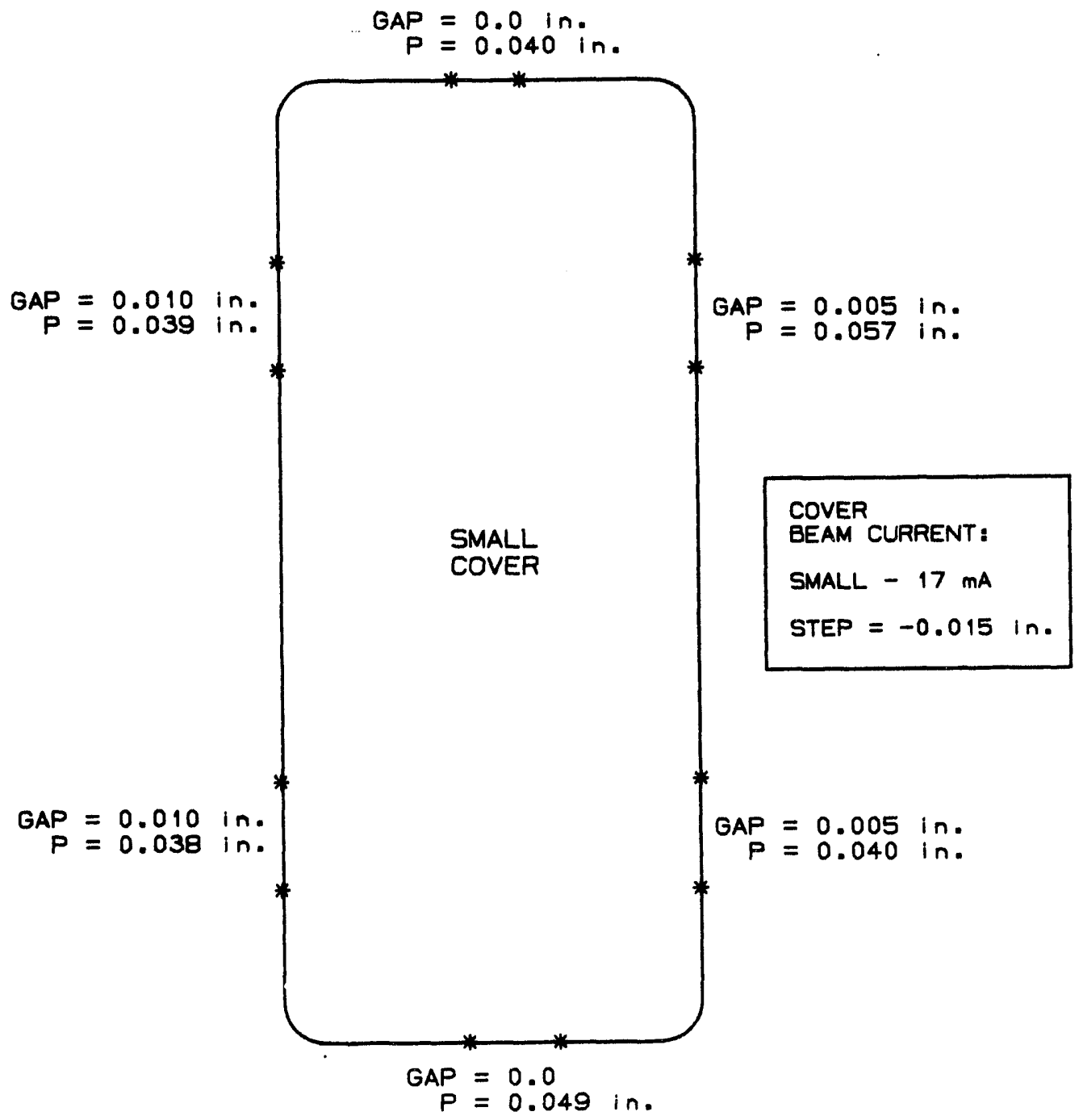

Flgure 22. Joint Tolerances Machined Into Cast Weldment for the Small Cover Weld 


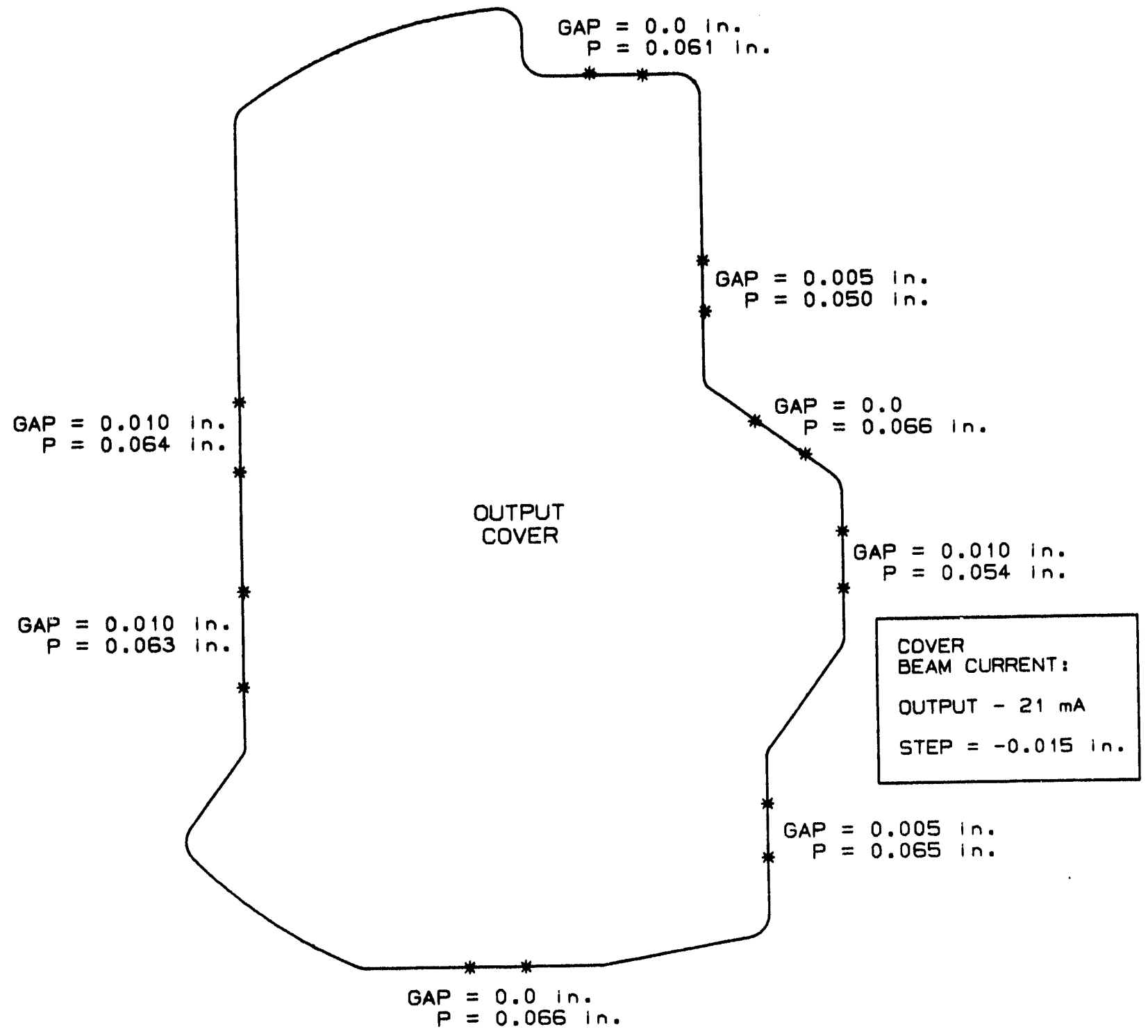

Figure 23. Joint Tolerances Machined Into Cast Weldment for the Output Cover Weld 


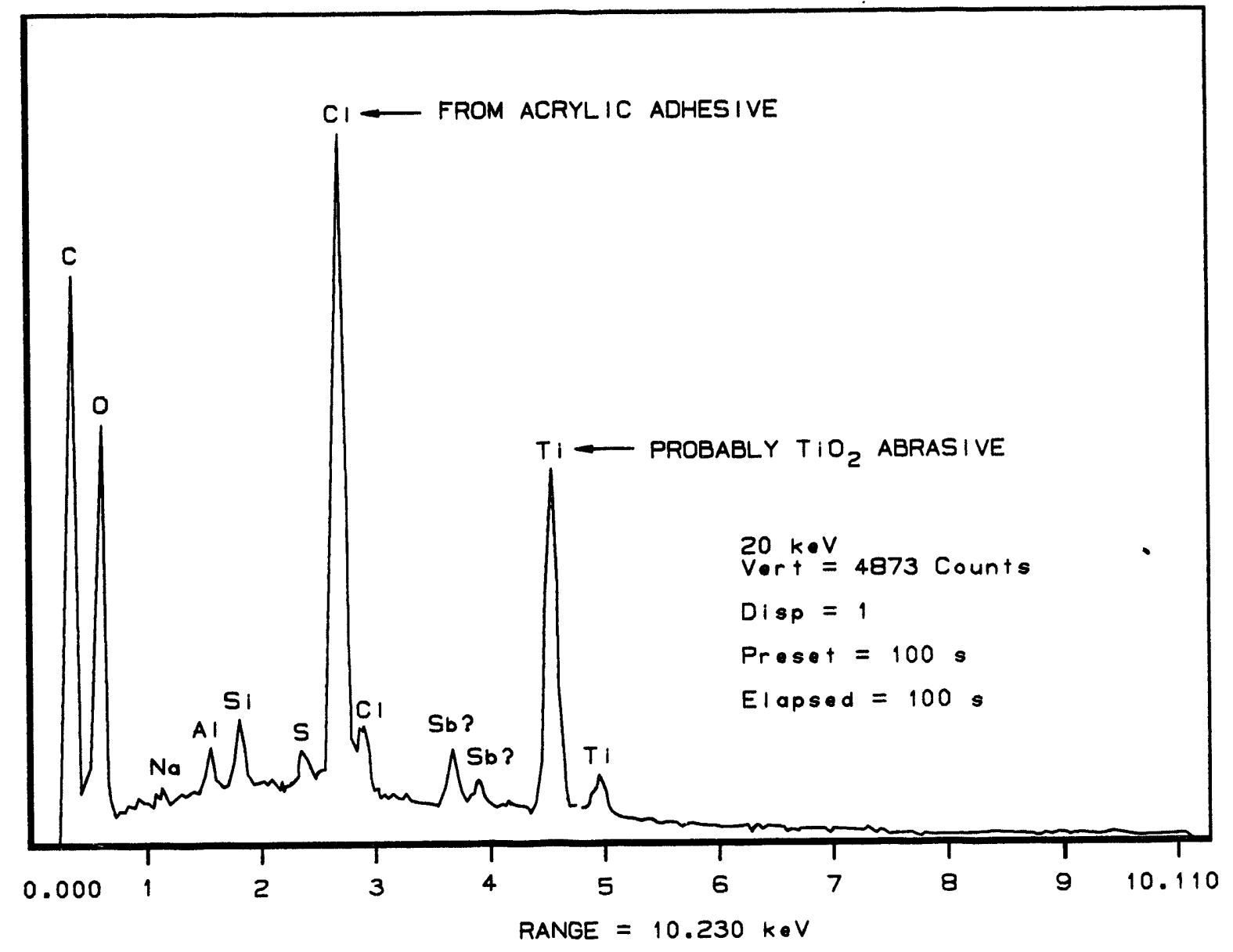

Figure 24. Elemental Analysis of Polyester Fiber Cleaning Material 


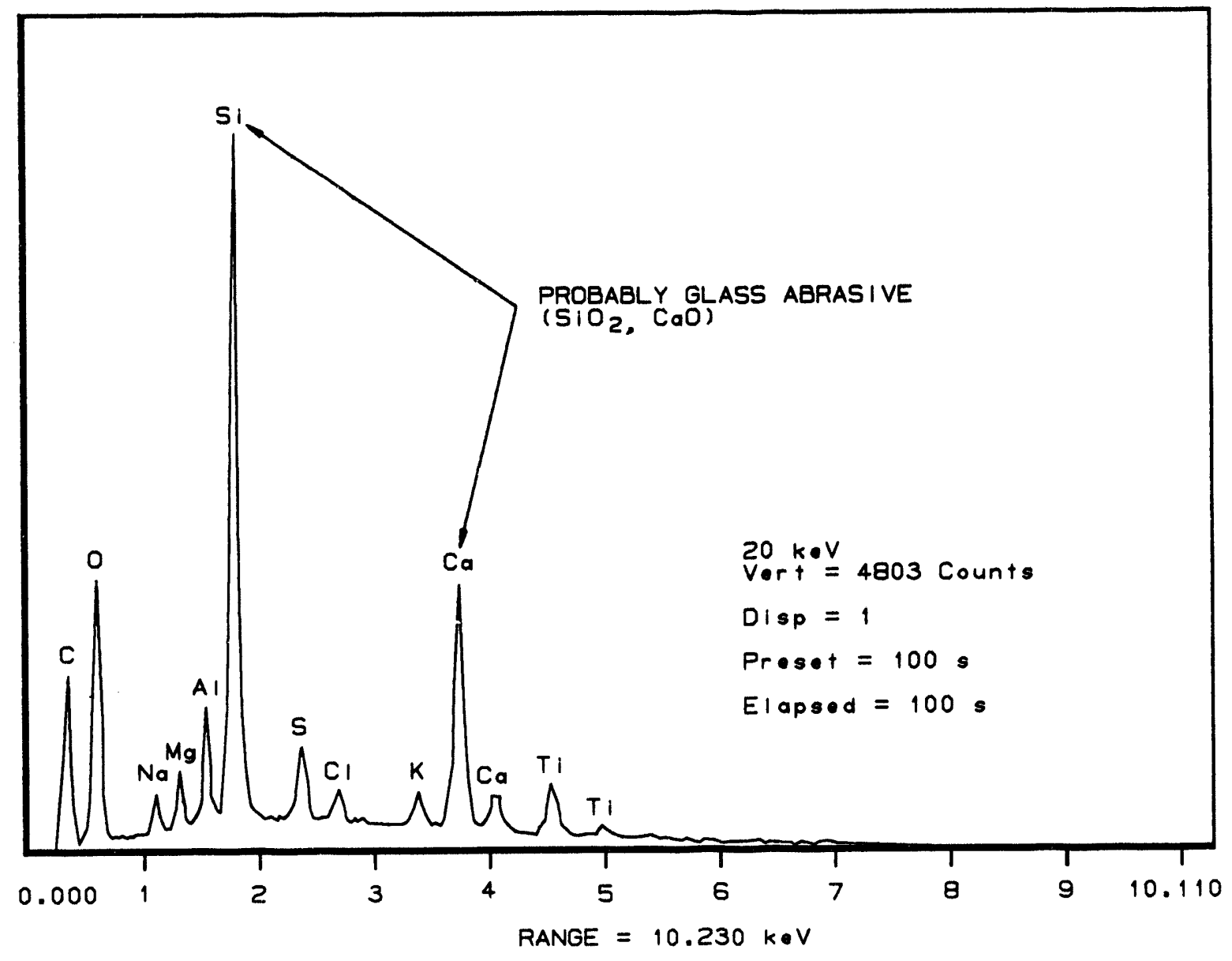

Figure 25. Elemental Analysis of Pen Eraser 


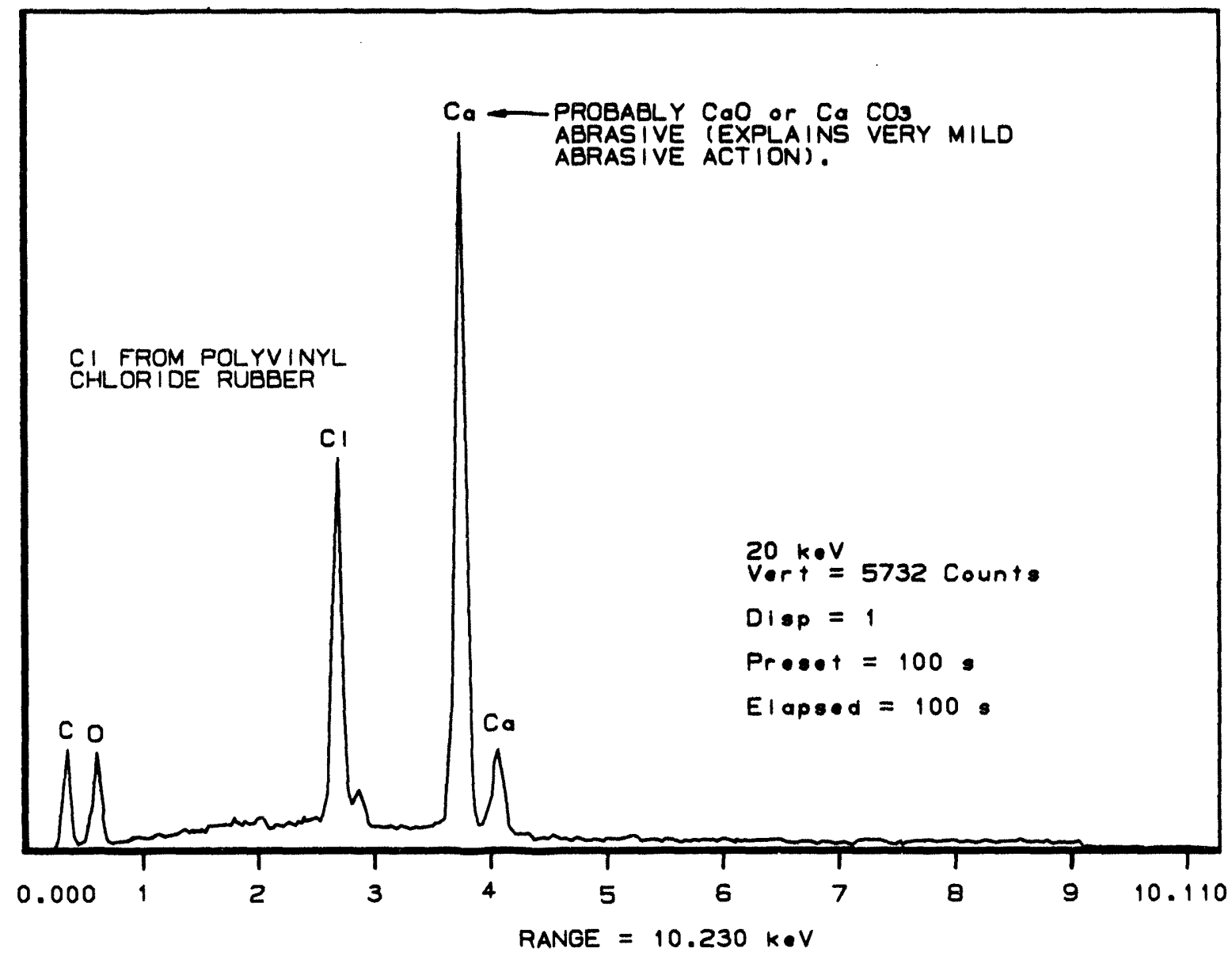

Figure 26. Elemental Analysis of Pencil Eraser

Table 5. Maximum Recommended Peak Temperature Exposure Component Maximum Temperature $(O C)$

Electrical Filters

Ceramic Capacitor

Solder Joints (60-40 Tin Lead)

Electrical Wire (PTFE insulated 600 VoHS RMS)

Papi Foam
125 (Exposed to $2600 \mathrm{C}$ Briefly from Solder Iron Tip Contact

150

183

290

205 (Starts to Yellow) 


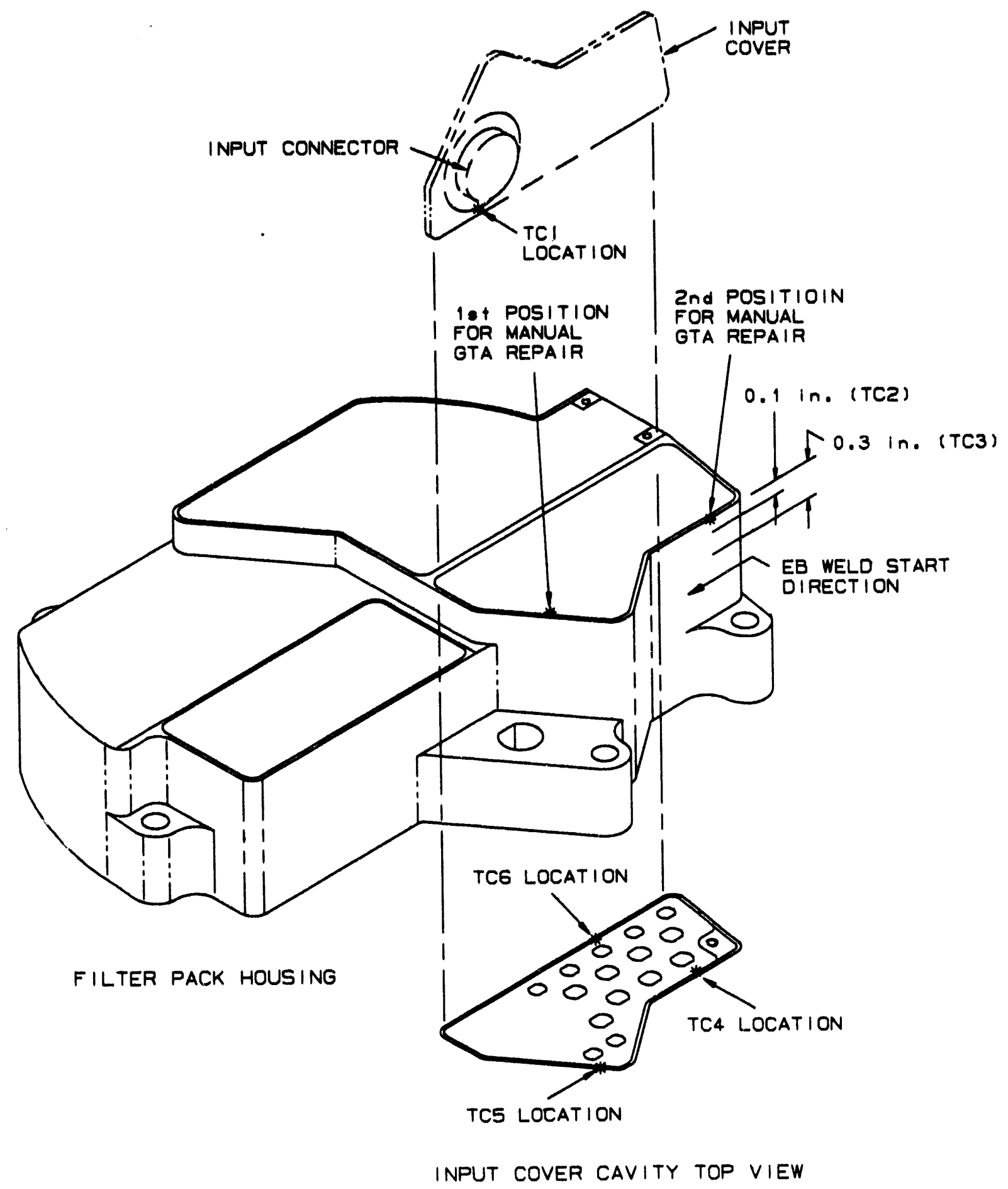

Figure 27. Thermocouple Locations on Cast Weldment 
Table 6. Peak Temperature Values on Input Cover Welds Thermocouple Number GTA Peak Temp. EBW Peak Temp. (OC)

\begin{tabular}{lll}
\hline TC1 & 143 & 83 \\
TC2 & No Data & 163 \\
TC3 & No Data & 113 \\
TC4 & 62 & 58 \\
TC5 & 62 & 55 \\
TC6 & 62 & 62 \\
Top Surface Input Cover & No Data & 41
\end{tabular}

Table 7. Peak Temperature Values on Input Cover GTA Repair

Weld Time TC1 $\mathrm{TC2}$ TC3 TC4 TC5 TC6 Temp.

(s) $\quad(O C) \quad(O C) \quad(O C) \quad(O C) \quad(O C) \quad(O C) \begin{aligned} & \text { Surface } \\ & (O C)\end{aligned}$

\begin{tabular}{llllllll}
\hline $\begin{array}{l}\text { Around } \\
\text { Connector }\end{array}$ & & & & & & & \\
7 & 77 & 35 & 35 & 35 & & 35 & 35 \\
15 & 102 & 35 & 35 & 35 & 35 & 40 & 42 \\
30 & 155 & 50 & 50 & 50 & 89 & 58 & 72 \\
$\begin{array}{l}\text { Near } \\
\text { Start }\end{array}$ & & & & & & & \\
7 & 40 & 300 & 226 & 77 & 40 & 45 & 52 \\
15 & 52 & 355 & 263 & 118 & 52 & 64 & 110 \\
30 & 66 & 387 & 307 & 158 & 70 & 91 & 143
\end{tabular}




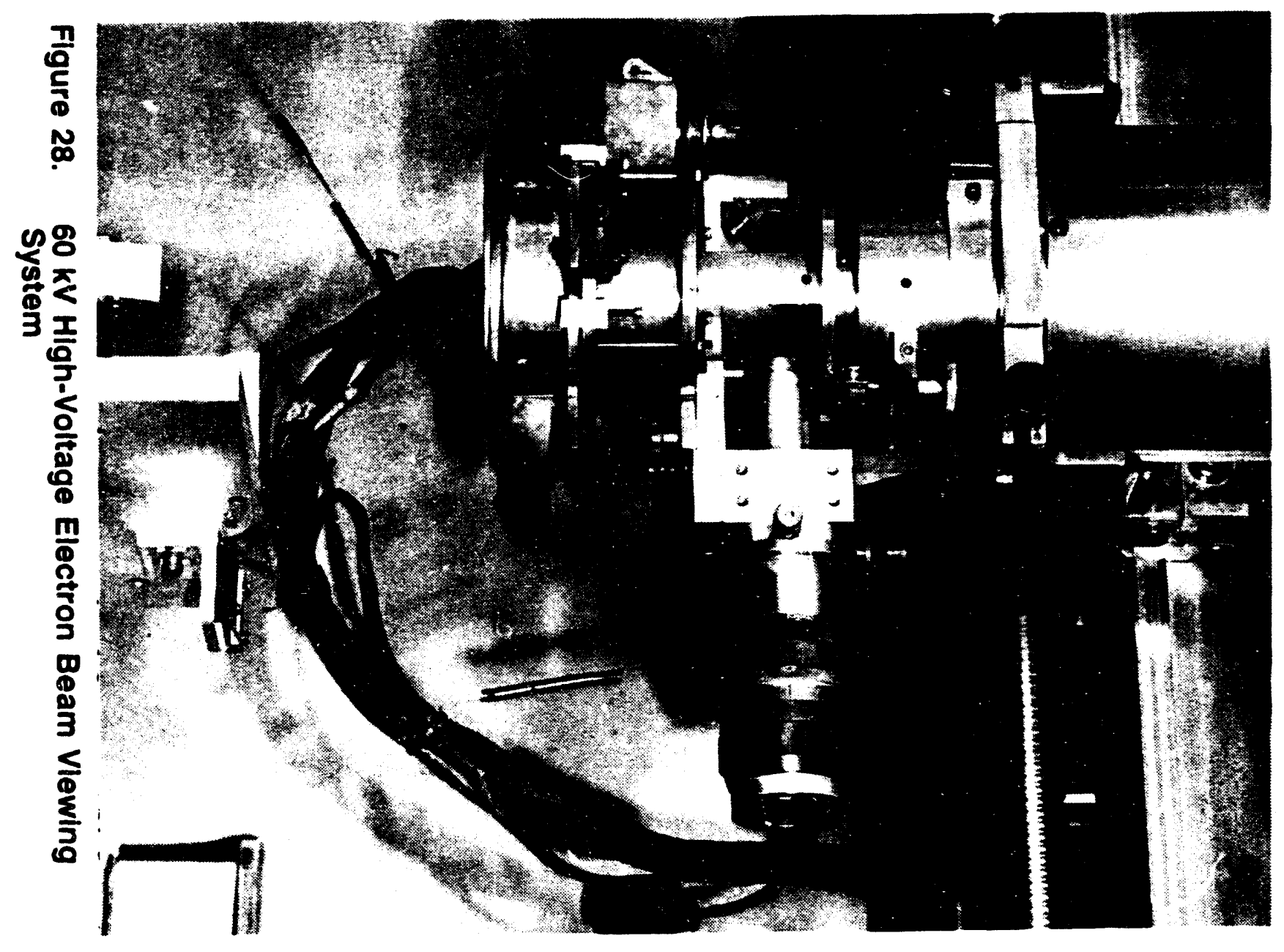




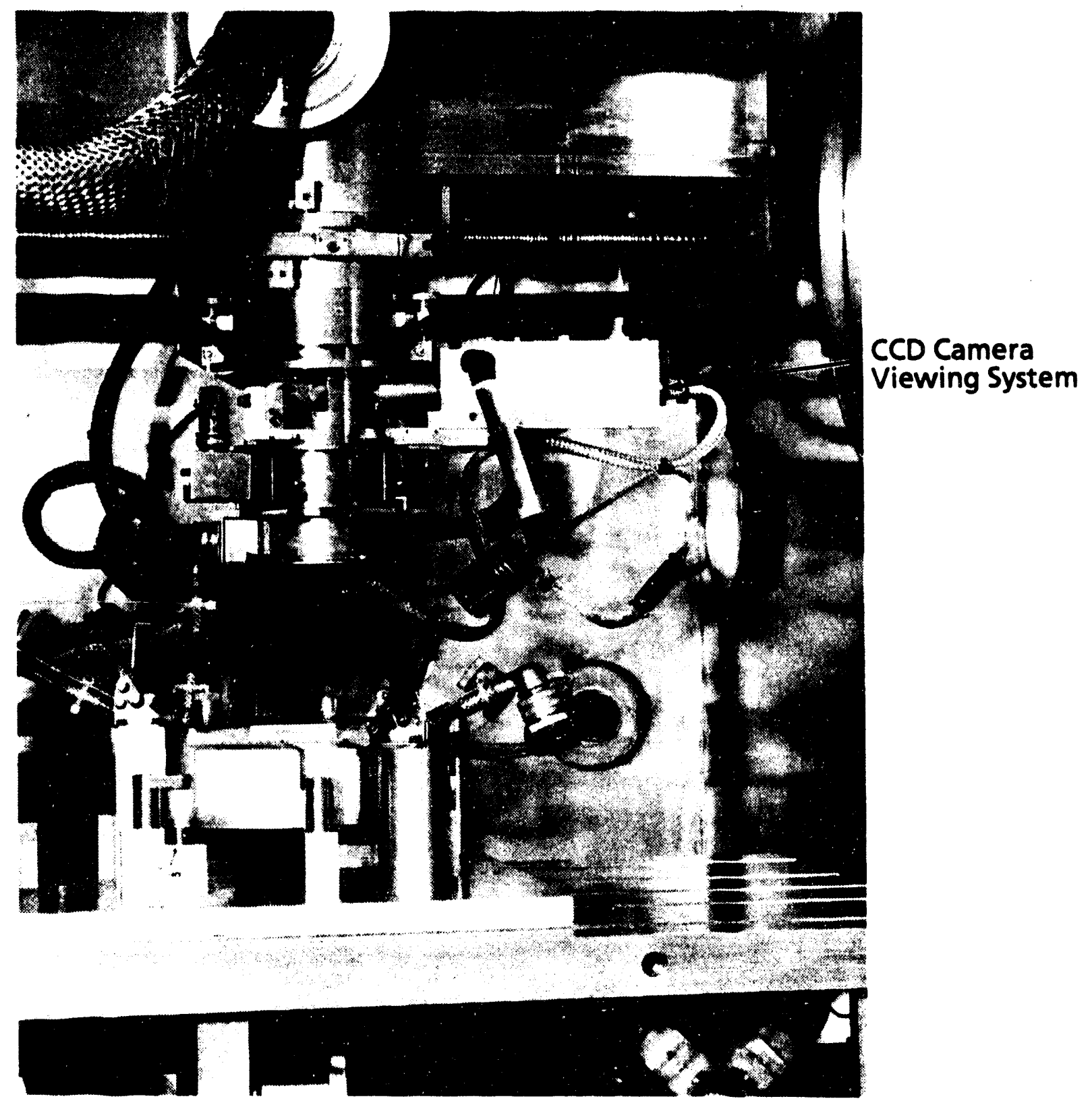

Figure 29. Improved Vlewing System on $60 \mathrm{kV}$ Electron Beam Welding System 


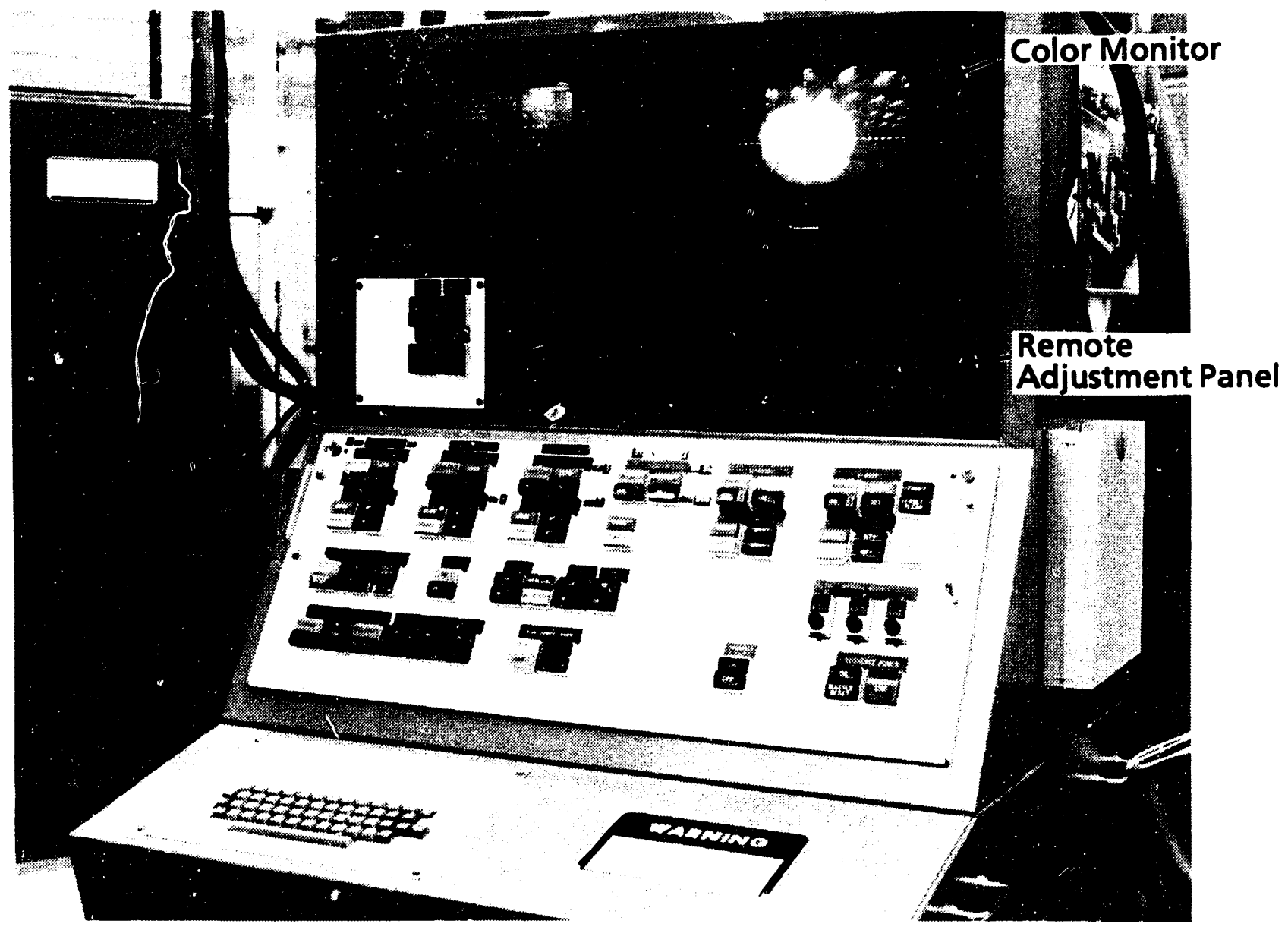

Figure 30. Modifled Electron Beam Control Cabinet 


\section{References}

'G. P. Miller, Electron Beam Welding of 6061-T6 Covers to A356-T6 Machined Cast Housings (Final Report). Kansas City Division: BDX-613-3915, March 1988 (Available from NTIS).

2E. D. Brandon, The Electron Beam Weldability of Aluminum Alloys A356 and 6061 and the Effect of Alodine Coating on the Weld Soundness, Sandia National Laboratory, January 1993. 


\section{Appendix}

Initial WPS Qualification Micrographs 


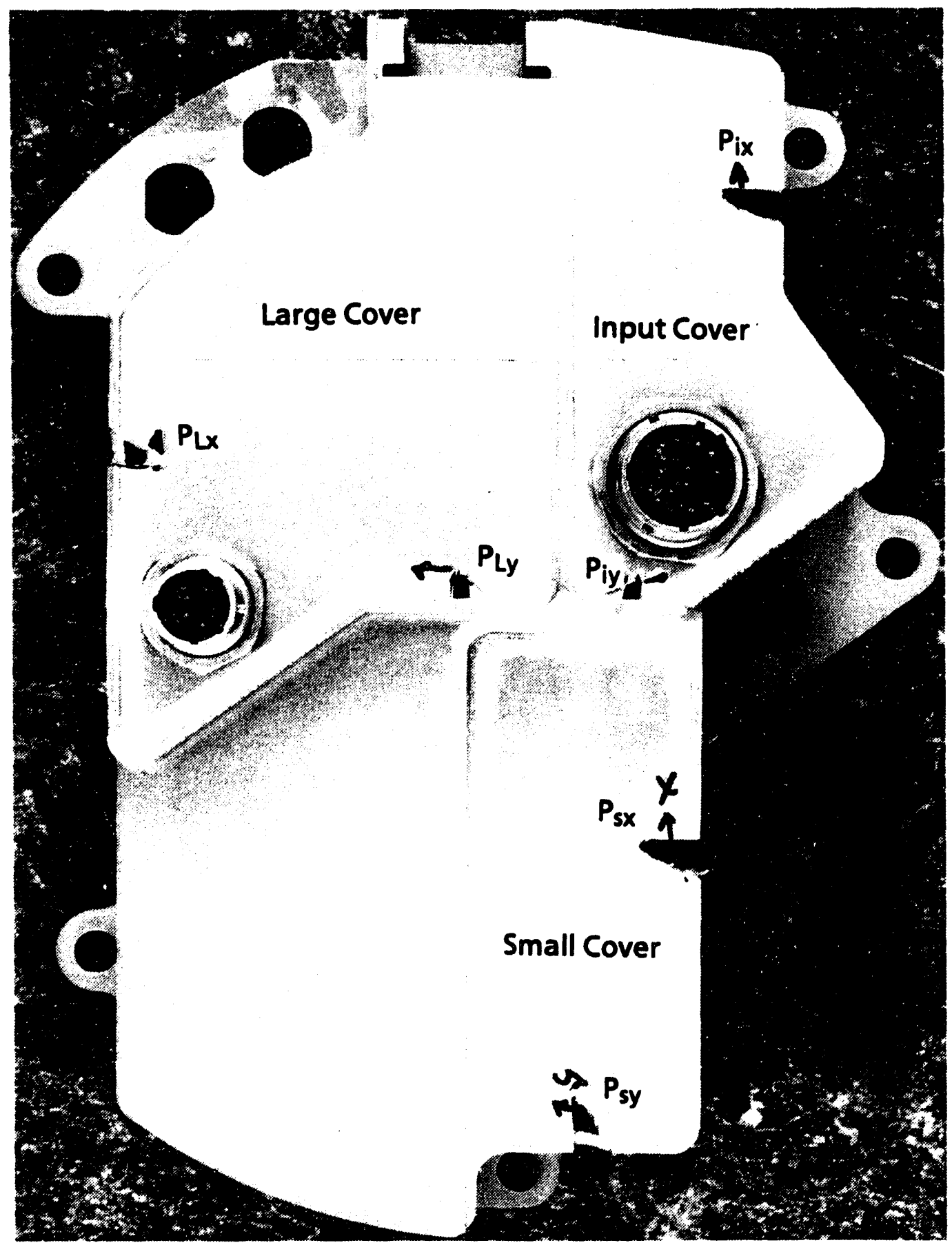

Figure A-1. Qualification Test Weldment Showing Cross-Sectional Locations on the Input Large and Small Covers 


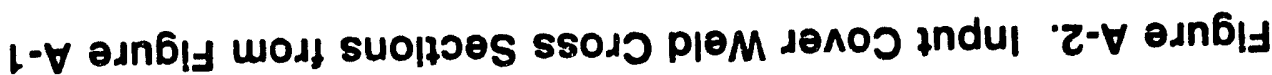

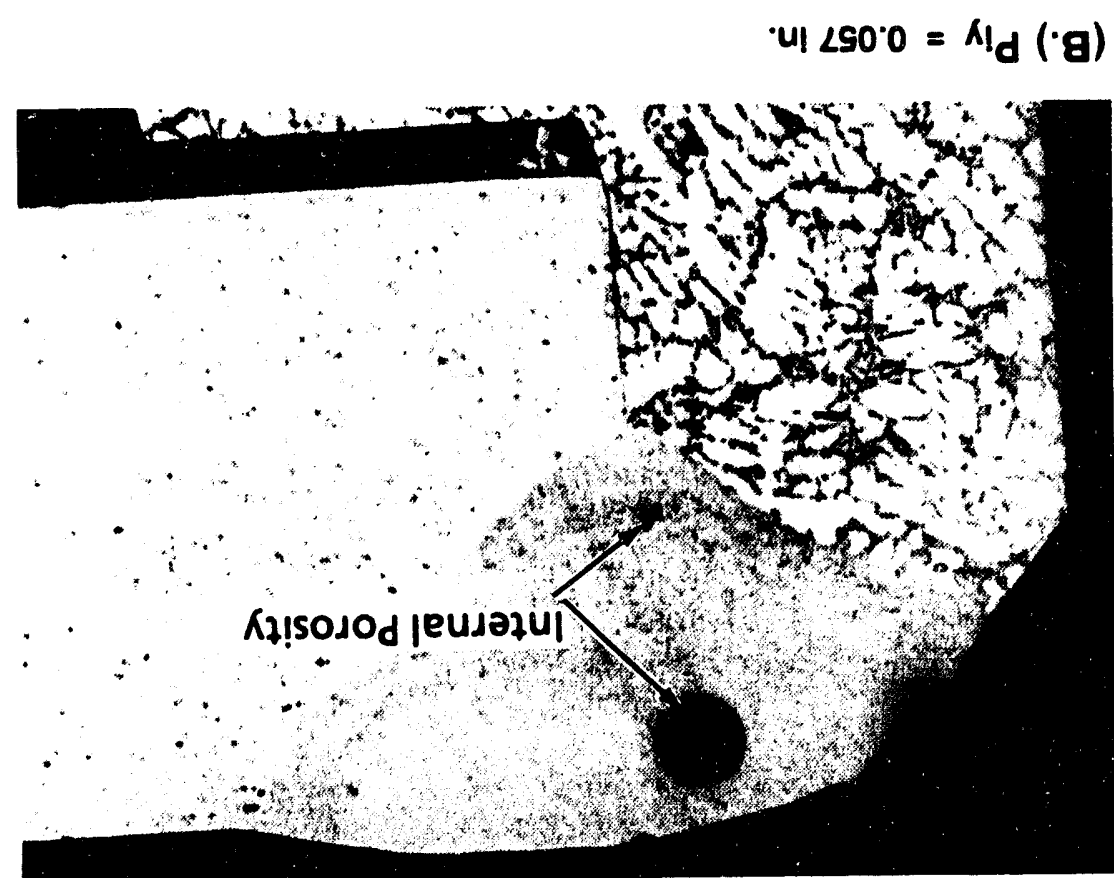

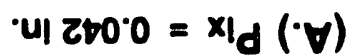

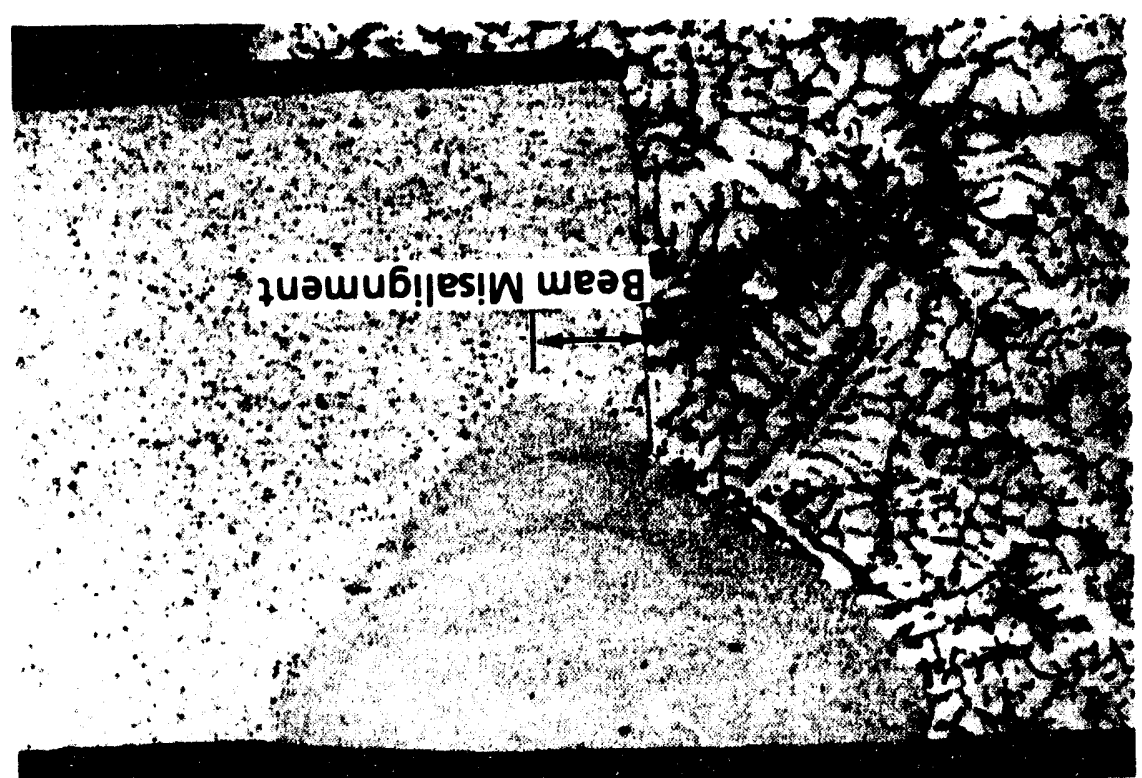




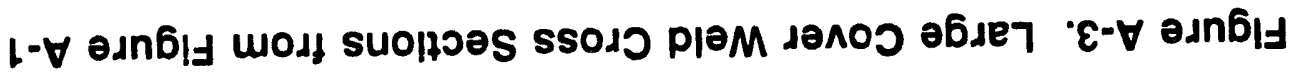

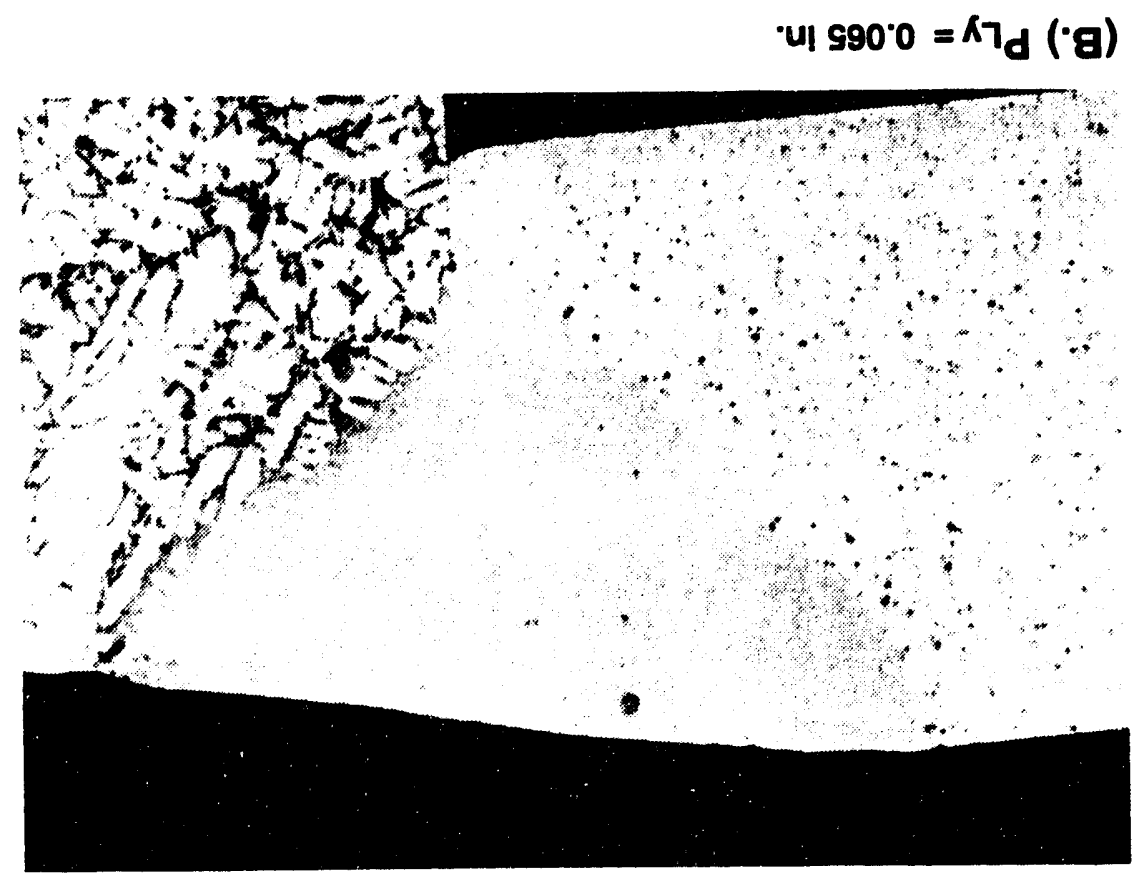

ul $890^{\circ} 0=x 7 d(\cdot v)$

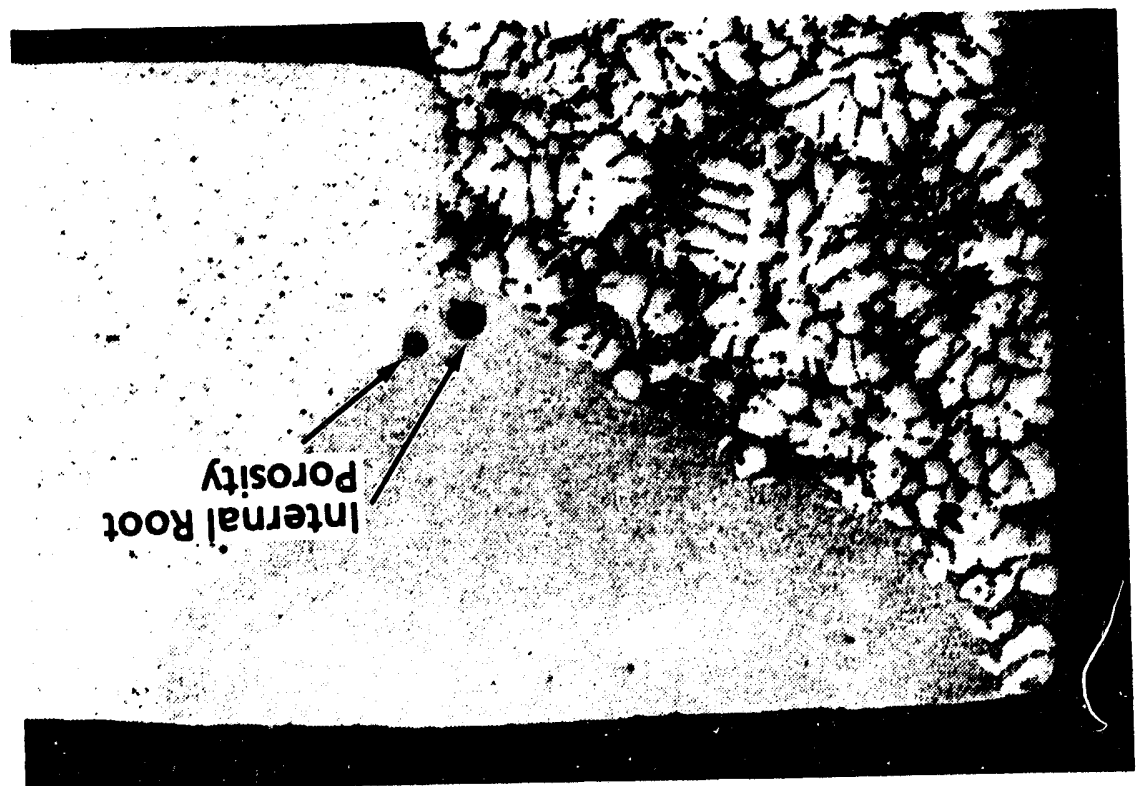




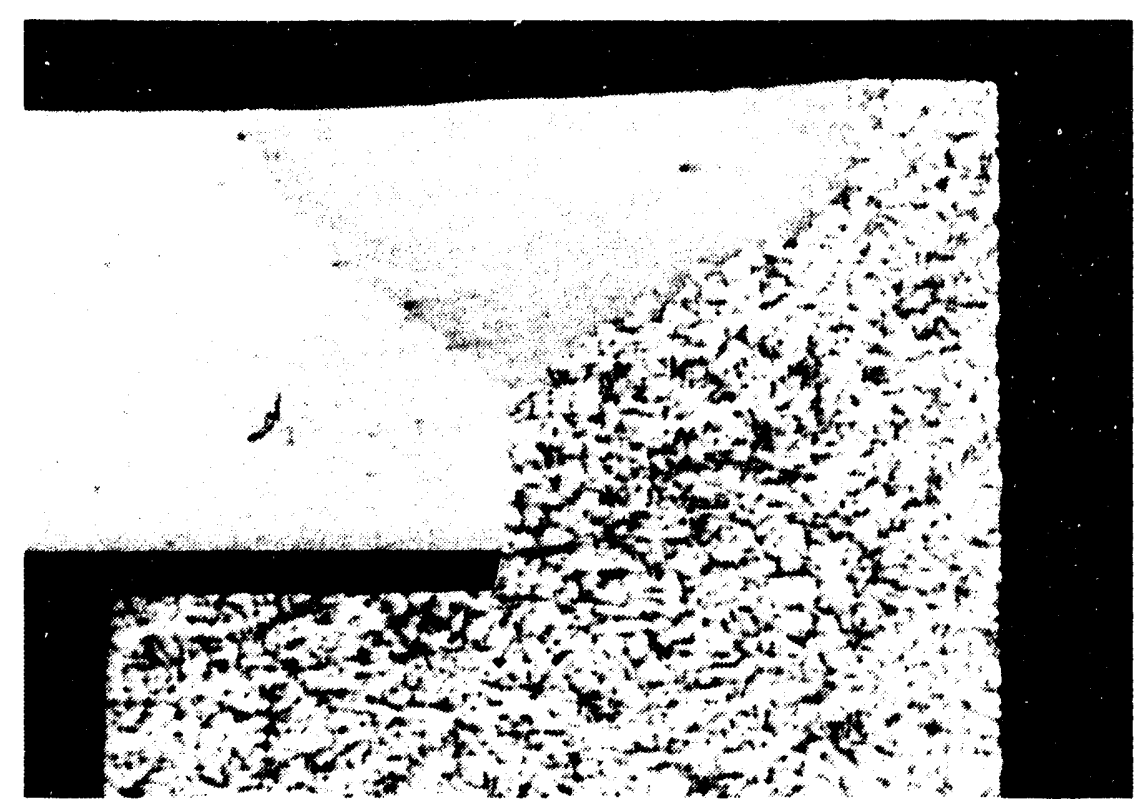

(A) $P_{5 x}=0.040$ in.

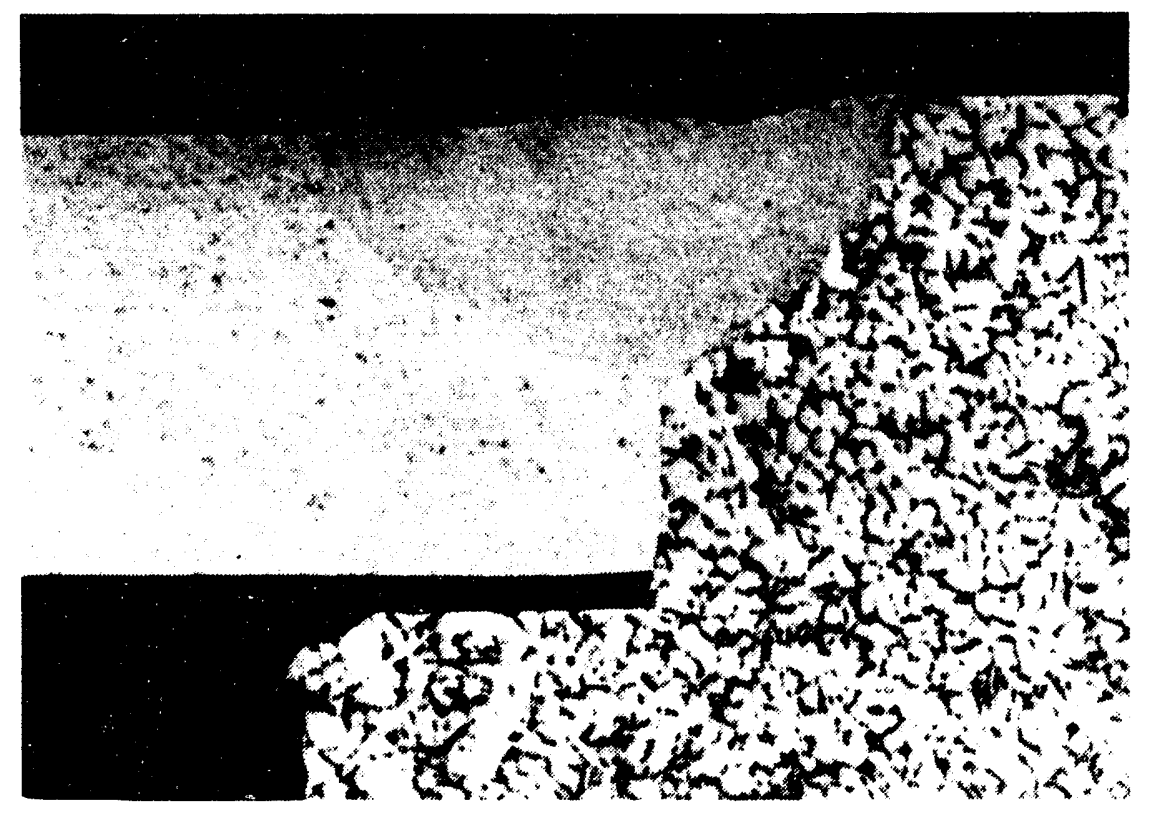

(B) $P_{\text {sy }}=0.038$ in.

Figure A-4. Small Cover Weld Cross Sections from Figure A-1 


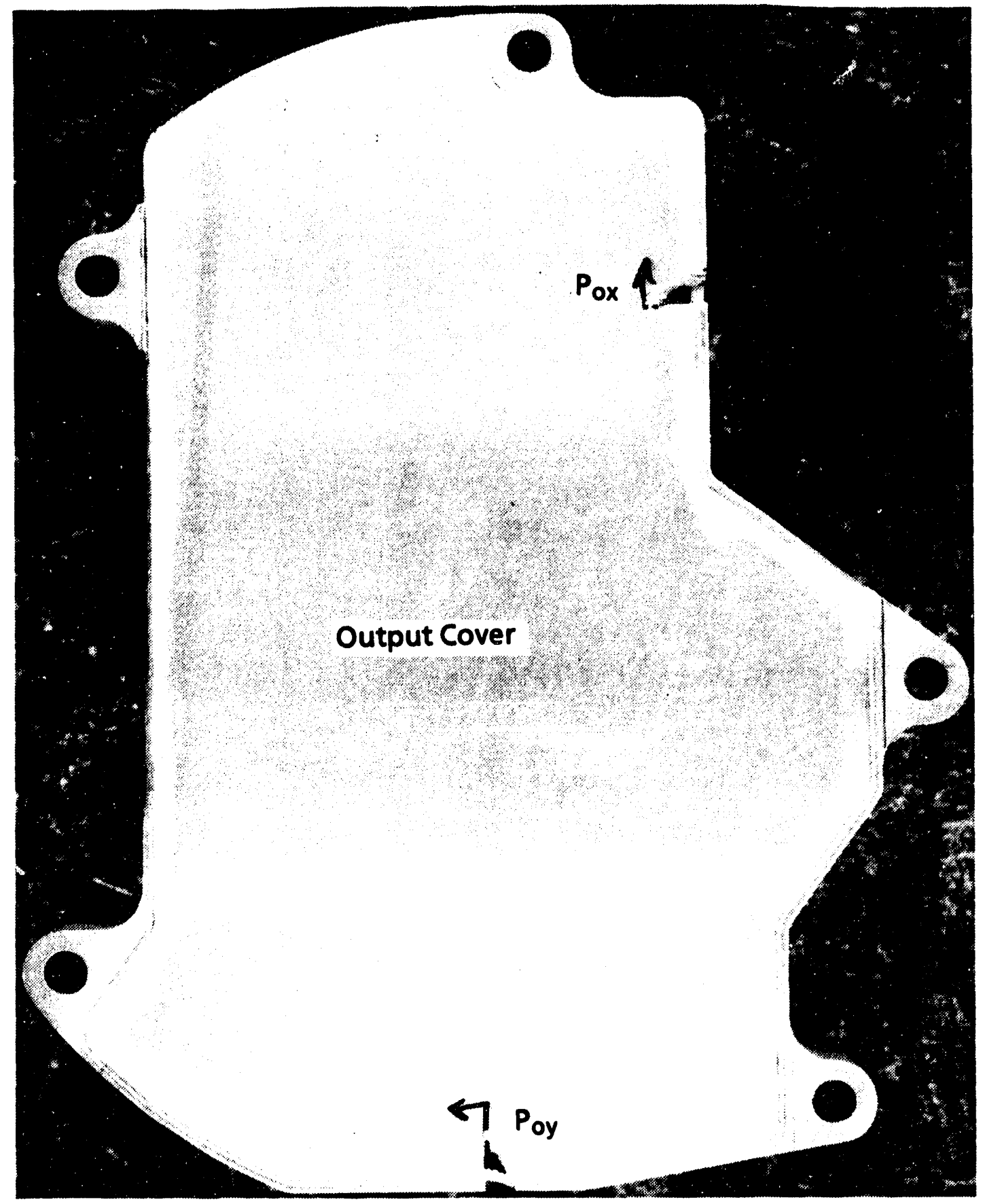

Figure A-5. Qualification Test Weldment Showing Cross-Sectional Locations on the Output Cover 


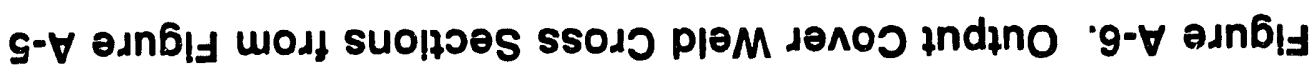

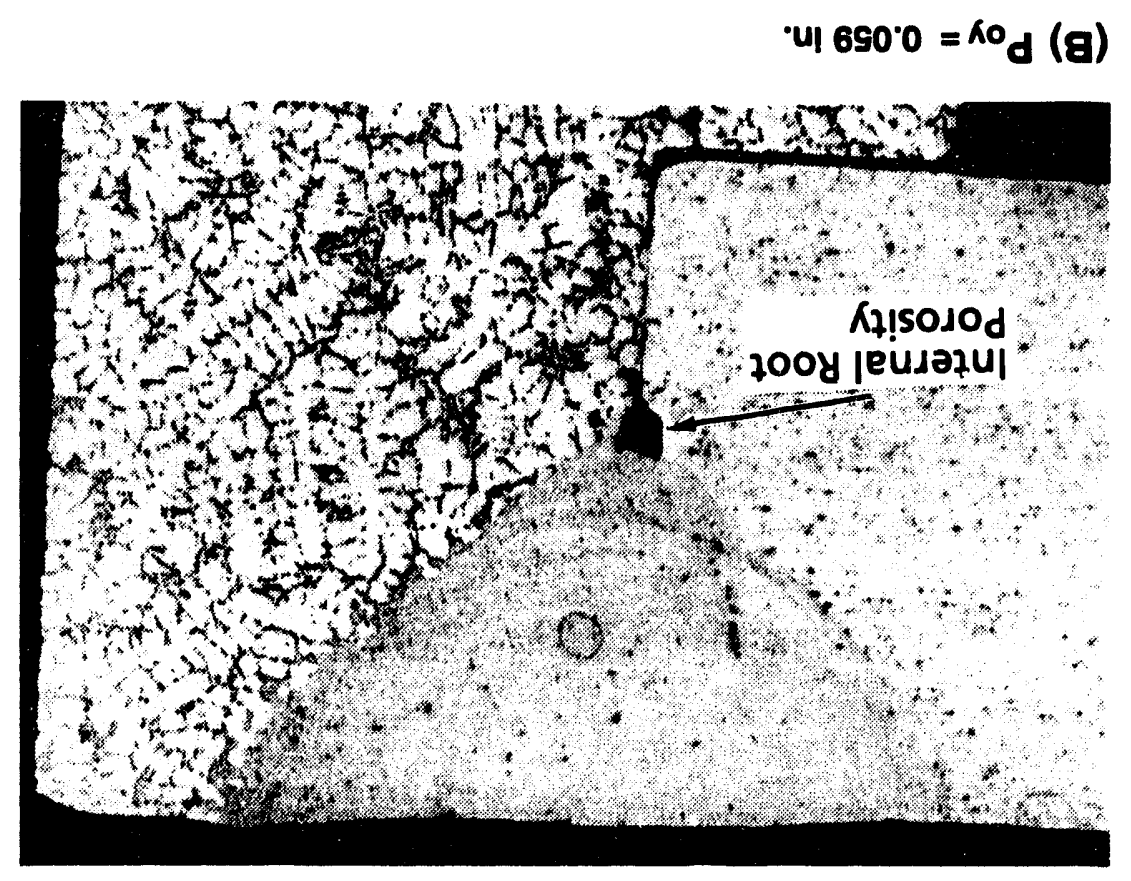

ul $\$ 60 \cdot 0=x_{0} d(\forall)$

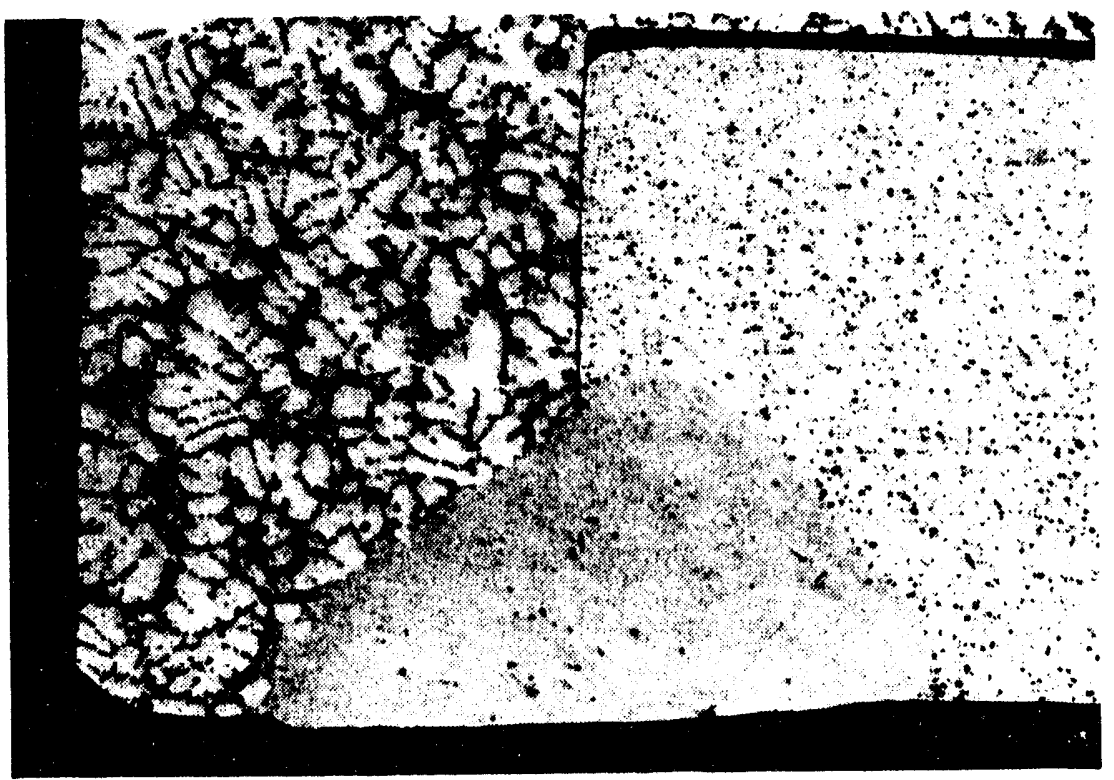



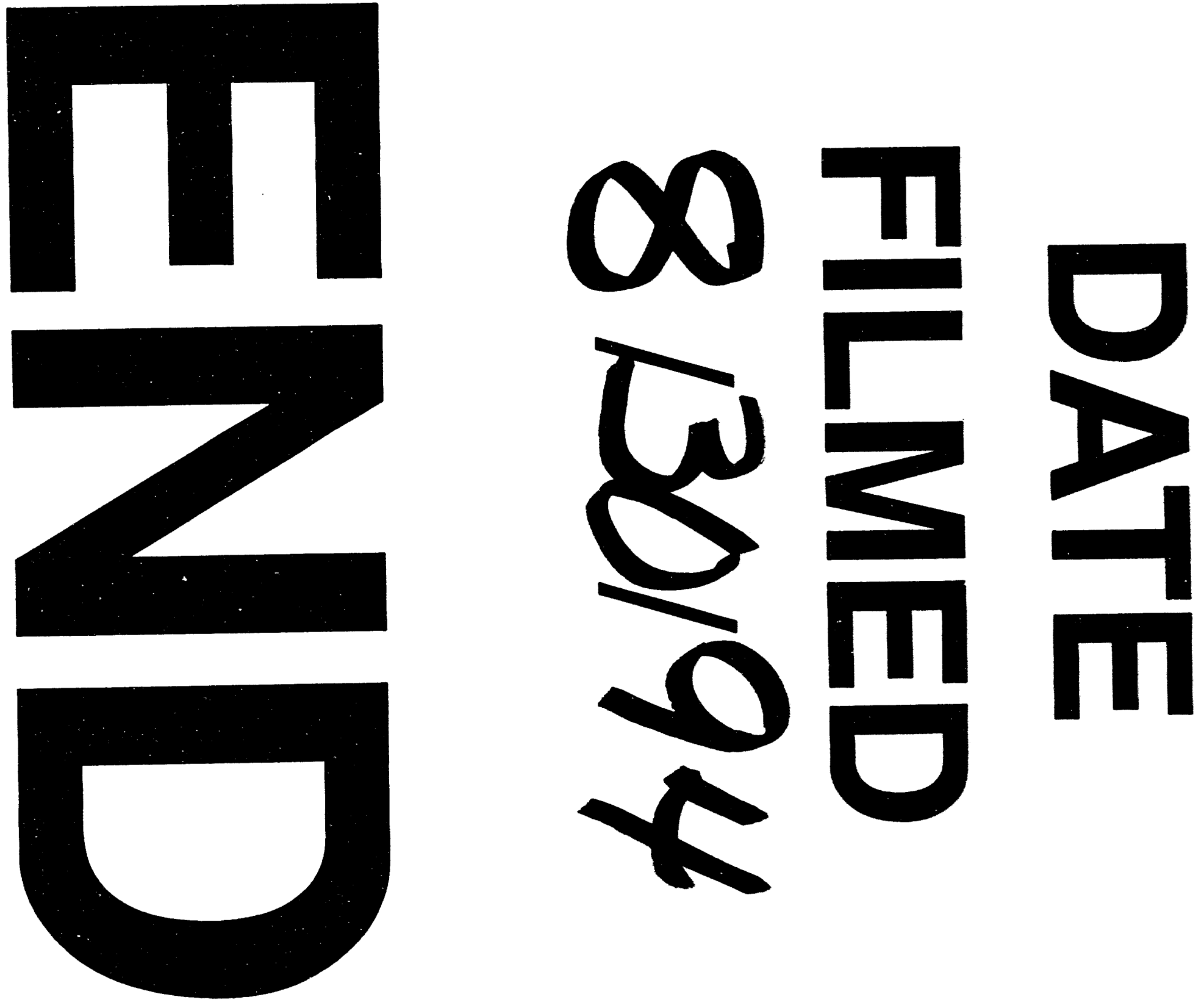


$$
\text { ( }
$$$$
\text { 更 }
$$

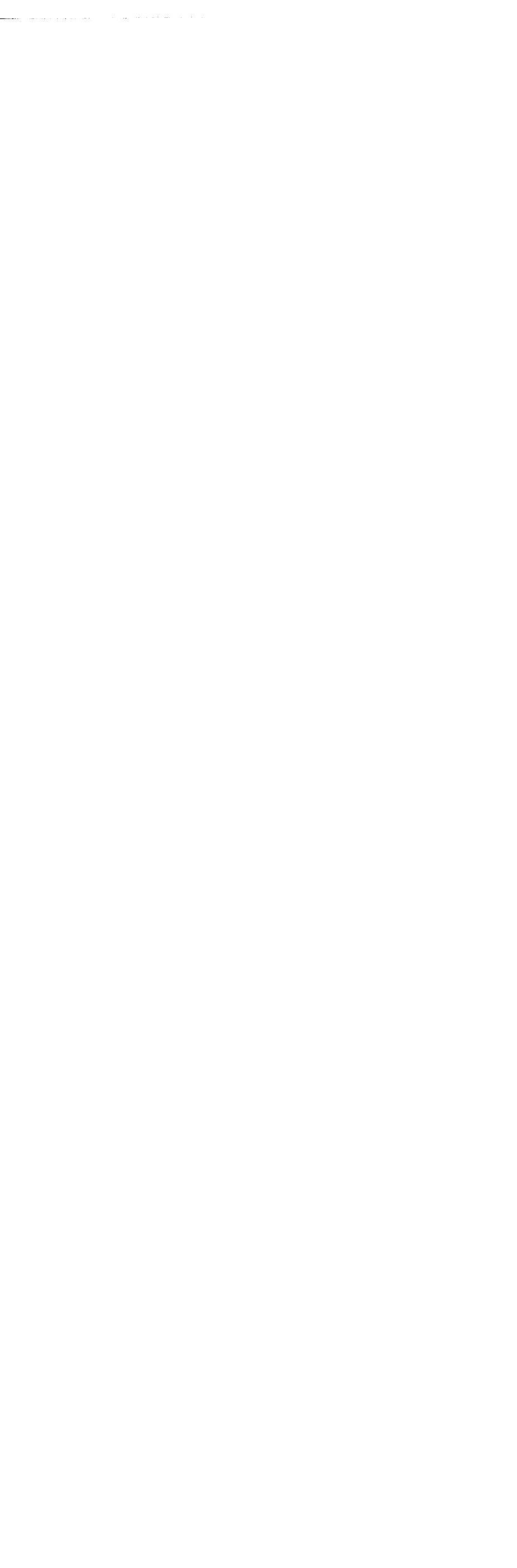

